\title{
The Nanostructured Secretome
}

S. Busatto ${ }^{1,2,3}$, A. Zendrini ${ }^{4}$, A. Radeghieri ${ }^{1,3}$, L. Paolini ${ }^{1,3}$, M. Romano ${ }^{1}$, M. Presta ${ }^{1}$, P. Bergese ${ }^{* 1,3}$.

1. Department of Molecular and Translational Medicine, University of Brescia, 25123 Brescia, Italy

2. Department of Transplantation Medicine; Department of Physiology and Biomedical

Engineering, Mayo Clinic, Jacksonville, FL 32224, USA

3. CSGI, Research Center for Colloids and Nanoscience, 50019 Florence, Italy

4. Department of Animal Science, Food and Nutrition - Università Cattolica del Sacro Cuore, 29122 Piacenza, Italy

*paolo.bergese@unibs.it

\begin{abstract}
The term secretome, which traditionally strictly refers to single proteins, should be expanded to also include the great variety of nanoparticles secreted by cells ( $\operatorname{secNPs}$ ) into the extracellular space, which ranges from high-density lipoproteins of few $\mathrm{nm}$ to extracellular vesicles and fat globules of hundreds of $\mathrm{nm}$. Widening the definition is urged by the ever-increasing understanding of secNP role as regulators/mediators of key physiological and pathological processes, which also puts them in the running as breakthrough cell-free therapeutics and diagnostics. "made by cells for cells", secNPs are envisioned as a sweeping paradigm-shift in nanomedicine, promising to overcome the limitations of synthetic nanoparticles by unsurpassed circulation and targeting abilities, precision and sustainability. On a longer/wider perspective, advanced manipulation would possibly make secNPs available as building blocks for future "biogenic" nanotechnology. However, current knowledge is fragmented and sectorial (the majority of the studies being focused on a specific biological and/or medical aspect of a given secNP class or subclass), understanding of the nanoscale and interfacial properties limited and development of bioprocesses and regulatory initiatives in the early days. We believe new multidisciplinary competencies and synergistic efforts need to be attracted and augmented to step forward. This review will contribute to the effort by attempting for the first time to rationally gather and elaborate secNP and their traits into a unique concise framework - from biogenesis to colloidal properties, engineering and clinical translation disclosing the overall view and easing comparative analysis and future exploitation.
\end{abstract}

Keywords: secretome, nanoparticles, extracellular vesicles, lipoproteins, ferritin, fat globules 


\section{Introduction. The secretome nanoparticles}

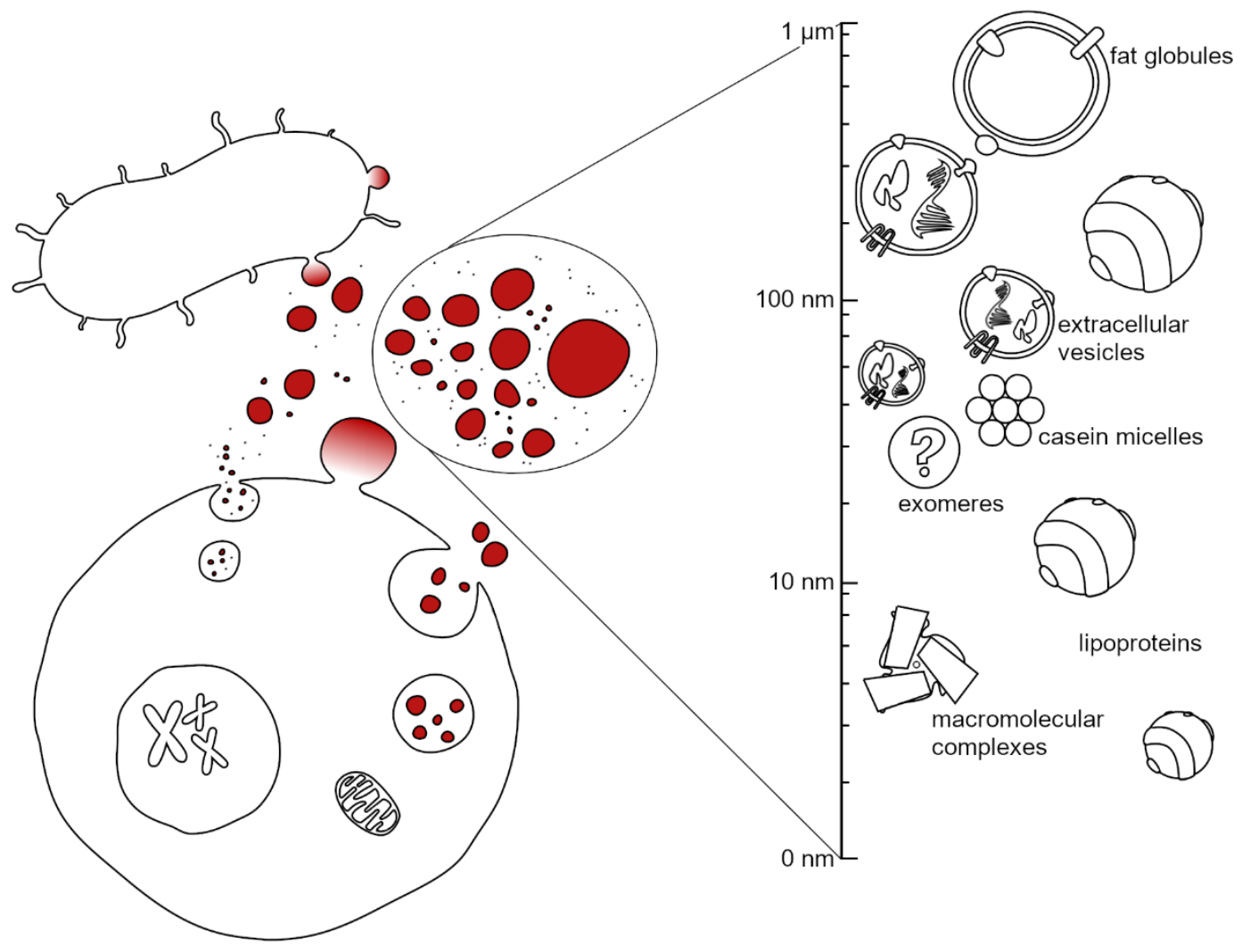

Figure 1. The nanostructured secretome sketched.

Cells, in both physiological and pathological conditions, secrete a great variety of nanoparticles (secNPs) with different composition, structure and function. SecNPs include macromolecular complexes (such as ferritin cui ${ }^{1}$ and RNA binding proteins) ${ }^{2}$, membranous particles (such as extracellular vesicles (EVs) ${ }^{3}$ and fat globules) ${ }^{4}$, and micellar structures (such as lipoproteins ${ }^{5}$ and casein micelles) ${ }^{6}$, with sizes that range from few to hundreds of nm (Figure 1). SecNPs are released into the extracellular space together with single molecules, with which they constitute an asset of all biological fluids - e.g. blood, cerebrospinal fluid, saliva, urine, milk - secNPs biological function is shaped by both their molecular and nanoscale (colloidal) properties ${ }^{7}$, that is by their composition, size, structure, surface charge, energetic stability, etc.

In the last years it is becoming more and more evident that cell-to-cell sharing of macromolecular information also occurs by secNPs, "nanolines" of communication that complement "classical" paracrine signalling of single proteins (often referred as soluble factors), such as cytokines, 
hormones and grow factors. ${ }^{8,9}$ In this way, secNPs participate in the regulation of normal physiological processes, such as stem cell maintenance or immune surveillance, and in the pathology underlying diseases.

For these reasons, in the last years secNPs are gaining exponential interest from both academia and biotech companies. Massive production of high grade secNPs is expected to foster a sweeping paradigm-shift in nanomedicine, by moving from the synthetic mainstream to natural and hybrid nanosystems "made by cells for cells" with unsurpassed circulation and targeting abilities, personalization and sustainability. Their medical translation might encompass oncology, immunology, tissue regeneration, neurodegenerative disorders and infectious and parasitic diseases. In addition, advanced understanding and manipulation would make secNPs available as effective building blocks for future "biogenic" nanotechnology.

However, current knowledge of the secNP palette is fragmented, sectorial (researches and reports are primarily focused on a specific biological and/or therapeutic function of a given kind of secNP) and uncomplete (understanding of the nanoscale, colloidal and interfacial properties is poor). On the other hand, the current conception of the secretome misses these nanosized components. As a first contribution to leap these hurdles, this review will rationally frame and describe all the secNPs into a unique and simple framework, disclosing the overall view and easing comparative analysis. SecNPs traits, which in the present specialized literature are scattered and/or 'buried', have been thoroughly reported and elaborated in the sections below, i.e. compositional, structural and colloidal properties (Section 2), concentration and separation methods, tweaking and engineering (Section 3). Follows an effective summary of secNP applications in nanomedicine, including drug delivery, vaccines, regenerative therapeutics and diagnostics (Section 4). The review closes with a discussion on secNP future exploitation and perspectives (Section 5).

Finally, it is worth noticing that this review focuses on biogenic nanoparticles spontaneously secreted by the cells. Therefore, nanosized cytoplasm organelles, viruses ${ }^{10}$ and fully artificial nanoparticles such as synthetic nanovesicles ${ }^{11}$ and DNA nanocages ${ }^{12}$ will not be considered. 


\section{Physicochemical and biological properties}

\subsection{Nanosized macromolecular complexes}

If not shielded by transport proteins, ions, RNAs, and hormones would be rapidly degraded by the enzymes that populate biological fluids. Albumin, ferritin, transferrin and argonaute-2 (Ago2) are just few examples of proteins that work as transient or regular carriers. Many of them are highly evolutionary ubiquitous ${ }^{1}$ and they all can be considered as secNPs naturally equipped with subnanoand/or nano-cages and pockets.

Albumin is the most abundant protein found in plasma. It is a small globular protein $(66 \mathrm{kDa})$ and has a high affinity for metals, fatty acids, amino acids, metabolites and lipophilic xenobiotics. ${ }^{13}$ The three-dimensional structure comprises three homologous domains that assemble to form a heart-shaped molecule. Each domain is a product of two subdomains and ligand binding regions are located in hydrophobic cavities in subdomains IIA and IIIA. ${ }^{14}$ Albumin most important physiological roles are: to bring solutes in the bloodstream to their target organs, to maintain the $\mathrm{pH}$ and osmotic pressure of plasma. ${ }^{15,16}$

The ferritin plays a key role in iron sequestration and its protein cages store excess cellular iron for future use by the cell. ${ }^{1,17}$ Ferritin consists of 24 subunits, typically comprised of different ratios of the $\mathrm{H}$ and $\mathrm{L}$ chain subunit. The different subunits have divergent functions $-\mathrm{H}$-ferritin utilizes ferroxidase activity for the oxidation of ferrous $\left(\mathrm{Fe}^{+}\right)$to ferric $\left(\mathrm{Fe}^{+}\right)$iron while L-ferritin contains acidic residues on the surface cavity that facilitate ferroxidase turnover and are crucial for the nucleation of $\mathrm{Fe}^{+}$within the core protein. Iron-free ferritin, named apoferritin (APOFe) consists in round-shaped hollow structure loadable with exogenous molecules, indeed ferritin can be disassembled at very acidic $(\mathrm{pH} 2-3)$ or very basic $(\mathrm{pH} 11-12) \mathrm{pH}$ and it self-reassembles at neutral $\mathrm{pH}$. These assembly properties have been used to load different compounds within the ferritin core. Recent studies demonstrated the association of $\mathrm{H}$-ferritin with exosomes, ${ }^{18,} 19$ another class of secNPs described hereafter, indicating that the intracellular trafficking and secretion of different secNPs can converge.

Transferrin is another important iron carrier that controls the toxic and insoluble characteristics of iron. Both apo- and holotransferrin are single-chain glycoproteins, with 670 - 690 amino acid residues and a molecular weight of $\sim 80 \mathrm{kDa}$. The transferrin molecule consists of two homologous lobes, termed N- and C-lobe. Each lobe consists of two domains that are connected by a flexible hinge, and each lobe can independently bind a Fe3+ ion. The highly specific 
binding site for $\mathrm{Fe} 3+$ is created when the two domains of a lobe close around the iron, whereas iron release requires the two domains to open up. ${ }^{20}$

Argonaute-2 (Ago2) is a ribonucleoprotein complex that serve as a carrier of circulating miRNAs in plasma and regulates small RNAs guided gene silencing processes. ${ }^{21}$ It is composed by four major domains: N, PAZ, MID and PIWI each with a specific function. The four domains array into a bi-lobe format consisting of N-PAZ and MID-PIWI connected by Linker 1/2 proteins. The two lobes form a gap which accommodates the guide small RNAs and their complementary fragments in the middle. ${ }^{22}$

The key physicochemical properties of nanosized macromolecular complexes are summarized in Figure 2. 


\begin{tabular}{|c|c|c|c|c|c|}
\hline \multicolumn{6}{|c|}{ nanosized macromolecular complexes } \\
\hline & \multicolumn{2}{|c|}{ albumin } & & \multicolumn{2}{|c|}{ argonaute 2} \\
\hline $\begin{array}{c}\text { shape } \\
\text { (hydrated) }\end{array}$ & \multicolumn{2}{|c|}{ oblate ellipsoid } & $\begin{array}{c}\text { shape } \\
\text { (hydrated) }\end{array}$ & \multicolumn{2}{|c|}{ oblate ellipsoid } \\
\hline size (crystal) & \multicolumn{2}{|c|}{$7.50 \mathrm{~nm} \cdot 6.50 \mathrm{~nm} \cdot 4.00 \mathrm{~nm}$} & size (crystal) & \multicolumn{2}{|c|}{$9.00 \mathrm{~nm} \cdot 5.48 \mathrm{~nm} \cdot 9.16 \mathrm{~nm}$} \\
\hline $\boldsymbol{R}_{\text {hyd }}$ & \multicolumn{2}{|c|}{$3.48 \mathrm{~nm}$} & $R_{\text {hyd }}$ & \multicolumn{2}{|c|}{ n.r. } \\
\hline $\boldsymbol{R}_{g y r}$ & \multicolumn{2}{|c|}{$2.74 \mathrm{~nm}$} & $\boldsymbol{R}_{g y r}$ & \multicolumn{2}{|c|}{ n.r. } \\
\hline pl & \multicolumn{2}{|c|}{5.67} & pl & \multicolumn{2}{|c|}{9.32} \\
\hline 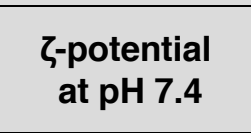 & \multicolumn{2}{|c|}{$\begin{array}{c}\text { n.r. } \\
(-13 \mathrm{mV} \text { at } \mathrm{pH} 6.5) \\
(-22 \mathrm{mV} \text { at } \mathrm{pH} 9.0)\end{array}$} & $\begin{array}{l}\text { ל-potential } \\
\text { at pH } 7.4\end{array}$ & \multicolumn{2}{|c|}{ n.r. } \\
\hline $\begin{array}{l}\text { physiological } \\
\text { concentration }\end{array}$ & \multicolumn{2}{|c|}{$0.5 \mathrm{mM}-0.7 \mathrm{mM}$} & $\begin{array}{l}\text { physiological } \\
\text { concentration }\end{array}$ & \multicolumn{2}{|c|}{ n.r. } \\
\hline$\rho$ & \multicolumn{2}{|c|}{$1.38 \mathrm{~g} \cdot \mathrm{cm}^{-3}$} & $\rho$ & \multicolumn{2}{|c|}{ n.r. } \\
\hline & \multicolumn{2}{|c|}{ transferrin } & & \multicolumn{2}{|c|}{ ferritin } \\
\hline & apotransferrin & holotransferrin & & apoferritin & holoferritin \\
\hline $\begin{array}{c}\text { shape } \\
\text { (hydrated) }\end{array}$ & \multicolumn{2}{|c|}{ prolate cylinder } & $\begin{array}{c}\text { shape } \\
\text { (hydrated) }\end{array}$ & \multicolumn{2}{|c|}{ roughly spherical } \\
\hline size (crystal) & \multicolumn{2}{|c|}{$8.02 \mathrm{~nm} \cdot 4.28 \mathrm{~nm} \cdot 6.25 \mathrm{~nm}$} & size (crystal) & \multicolumn{2}{|c|}{$\begin{array}{c}12.00 \mathrm{~nm} \text { (outer shell) } \\
7.60 \text { (iron storage pocket) }\end{array}$} \\
\hline$R_{\text {hyd }}$ & $4.04 \mathrm{~nm}$ & n.r. & $R_{\text {hyd }}$ & $6.10 \mathrm{~nm}$ & n.r. \\
\hline $\boldsymbol{R}_{\text {gyr }}$ & \multicolumn{2}{|l|}{$3.30 \mathrm{~nm}$} & $R_{g y r}$ & $5.60 \mathrm{~nm}$ & $\begin{array}{c}3.70 \mathrm{~nm} \\
\text { (protein) } \\
2.90 \mathrm{~nm} \\
\text { (iron core) }\end{array}$ \\
\hline pl & 6.70 & n.r & pl & $\begin{array}{l}5.30 \text { (H-chain) } \\
5.50 \text { (L-chain) }\end{array}$ & n.r. \\
\hline $\begin{array}{l}\text { ל-potential } \\
\text { at pH } 7.4\end{array}$ & n.r. & $-8.20 \mathrm{mV}$ & $\begin{array}{l}\text { Z-potential } \\
\text { at pH } 7.4\end{array}$ & n.r. & n.r. \\
\hline $\begin{array}{l}\text { physiological } \\
\text { concentration }\end{array}$ & \multicolumn{2}{|c|}{$25.00 \mu \mathrm{M}-45.00 \mu \mathrm{M}$} & $\begin{array}{l}\text { physiological } \\
\text { concentration }\end{array}$ & \multicolumn{2}{|c|}{$4.80 \mathrm{pM}-70.00 \mathrm{pM}$} \\
\hline$\rho$ & $1.41 \mathrm{~g} \cdot \mathrm{cm}^{-3}$ & n.r & $\rho$ & $1.27 \mathrm{~g} \cdot \mathrm{cm}^{-3}$ & $1.45 \mathrm{~g} \cdot \mathrm{cm}^{-3}$ \\
\hline
\end{tabular}


Figure 2. Physicochemical properties of primary macromolecular complex secNPs. Size was estimated from RSCB PDB files 1AO6, ${ }^{15} 3 \mathrm{QYT},{ }^{23} 2 \mathrm{FHA}^{24}$ and 5JS2. ${ }^{25}$ Albumin, apotransferrin, apoferritin and $\mathrm{AGO} 2$ isoelectric points were predicted using ExPASy compute $\mathrm{pI} / \mathrm{Mw}$ tool (https://web.expasy.org/compute pi/). Other data obtained from. ${ }^{26-31}$ Unknown parameters are here marked as "n.r." (not reported). Notes: i) reported protein concentrations refer to human adult males; concentrations relative to adult females and infants are slightly lower; ii) some of the parameters reported refer to bovine or horse counterpart (which anyway closely resemble human variant in term of structure and sequence); iii) mean protein density is experimentally considered to be $1.35 \mathrm{~g} \cdot \mathrm{cm}^{-3}$, while theoretical calculation performed on standard proteins led to a mean density of $1.47 \mathrm{~g} \cdot \mathrm{cm}^{-3}$ or $1.43 \mathrm{~g} \cdot \mathrm{cm}^{-3}$, in regards of the algorithm used to perform the analysis. ${ }^{32}$,

${ }^{33}$ Legend: $R_{h y d}=$ hydrodynamic radius; $R_{g y r}=$ gyration radius; $p I=$ isoelectric point; $\rho=$ density.

\subsection{Extracellular vesicles}

Extracellular vesicles are soft nanoparticles made by a lipid membrane which encloses proteins, nucleic acids and metabolites (Figure 3 and Figure 4). They function in cell- cell and cellmicroenvironment communication, ${ }^{34,35}$ emerging as universal agents in intra- and cross-organism communication for mammalians, viruses, ${ }^{10}$ bacteria, archaea, microbes, parasites, ${ }^{36}$ fungi and plants. ${ }^{37}$

\subsubsection{Eukaryotic extracellular vesicles (EVS)}

Eukaryotic extracellular vesicles (EVs) are traditionally divided into exosomes and microvesicles (MVs) accordingly to their biogenesis. ${ }^{38}$ Exosomes originate from the intracytoplasmatic multivesicular bodies (MVBs) and are directly released into the extracellular space upon the fusion of the MVB membrane with the plasma membrane. Their size ranges from 30 to $250 \mathrm{~nm} .{ }^{39} \mathrm{MVs}$ instead directly bud from the plasma membrane and have a size ranging from 150 to $800 \mathrm{~nm} .{ }^{39}$ Exosomes and MVs partially overlap in size and share many of the known biomarkers enriched in EVs. Therefore, more recent nomenclature only refers to $30-250 \mathrm{~nm}$ size EVs as small EVs and to 150-800 nm size EVs as large EVs. ${ }^{40}$ Other peculiar physicochemical properties of these soft colloids are summarized in Figure 3. 
EVs are emerging as the third way for cell communication other than direct intercellular physical stimuli or the paracrine secretion of active molecules. ${ }^{35} \mathrm{EVs}$ act as vehicles for bioactive cargoes preventing their degradation and delivering them to target cells. Due to their structure and function EV actively participate to different physiological processes, such as coagulation and immune system activation. ${ }^{3,35}$ On the flip side, EV contribute to the effective maintenance and diffusion of several pathological processes that rely on cell-to-cell communication. For instance, it has been demonstrated that malignant tumours exploit EV-based strategies to initiate the pre-metastatic niche and colonize other healthy organs. ${ }^{41}$

EV can be found in every biological fluid deriving from common cell secretory pathways. Due to their biogenesis and structure, EVs are representative of the releasing cell phenotype, also resembling the originating cell functions (a "window into the cellular world"). ${ }^{37}$ On the other hand, EVs feature specific differential compositional enrichment, starting from lipids (Figure 4) and proteins (Section 4.4.2). For example, EVs isolated from mesenchymal stem cells (MSCs) reproduce part of the biological effects, particularly those responsible of their regenerative potential. MSCs actively secrete encased into EVs multiple growth factors and cytokines that stimulate the repair of different tissues and organs (for further details see Section 4.3.2). ${ }^{42}$

\subsubsection{Prokaryotic extracellular vesicles $(\mathrm{OMVS})$}

The vesicles released from microorganisms belonging to the prokaryotes domain originate from their outer membranes and are therefore nominated outer membrane vesicles (OMVs). Depending on the type of secreting cell, OMVs have different sizes that range from few tens of nm to $300 \mathrm{~nm}$ (Figure 3) and vary in lipid and protein composition. OMVs are secreted from prokaryotes in order to mediate both the release of virulent molecules and the communication with the surrounding cells and host organisms. For instance, bacteria present in poly-microbic environments release by OMVs set of mild antibiotic molecules to control and limit the growth of the surrounding unicellular species. Notably, the release of OMVs from prokaryotes is known to be activated and shaped by different environmental factors such as $\mathrm{pH}$, temperature, immune cell-secretome and is known to be fundamental in determining the pathogen adaptive response. In particular, OMVs seems to be the elective vehicles for lipopolysaccharide (LPS) and other virulent factors which mediate a large number of pathogenetic mechanisms. ${ }^{43}$ 


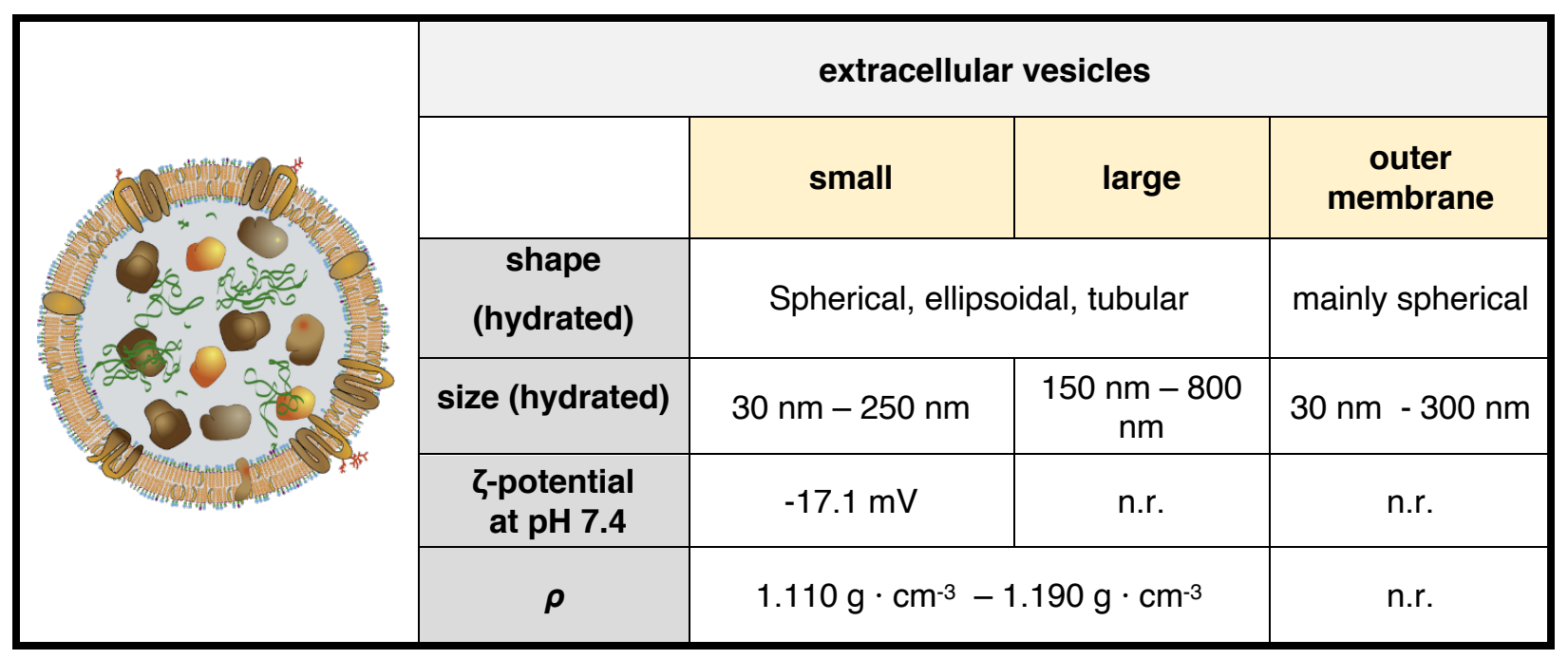

Figure 3. Physicochemical properties of extracellular vesicles (EVs). Notice that the reported $\zeta$ potential refers to serum EVs. ל-potential varies significantly depending on EV media (e.g. saliva, urine, blood, cerebrospinal fluid), and oscillates between $-15 \mathrm{mV}$ and $-34 \mathrm{mV}$. Unknown parameters are here marked as "n.r." (not reported). Figure adapted and reproduced from ref. ${ }^{3}$ with permission from Elsevier, copyright 2012. Data obtained from. ${ }^{44-46}$ Legend: $\rho=$ density 


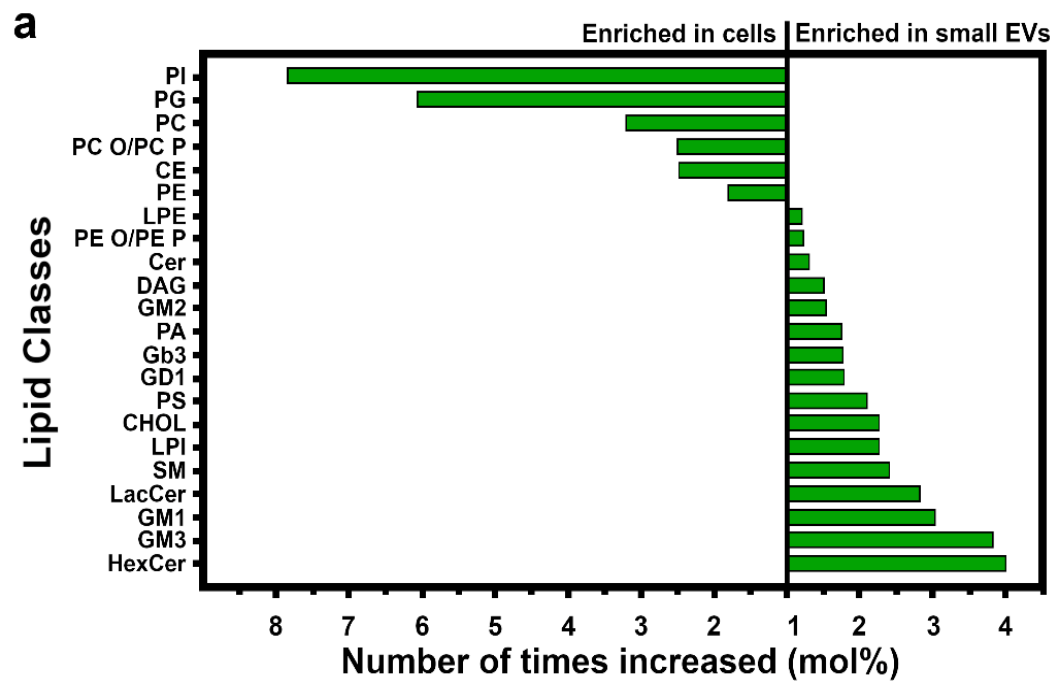

b

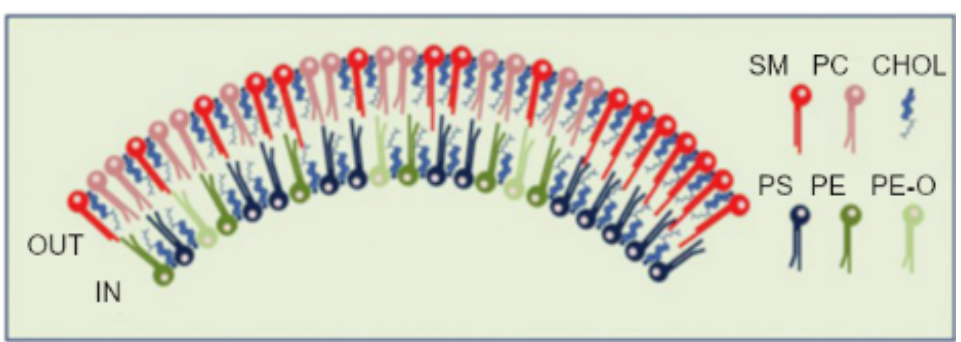

Figure 4. Lipid composition of small EVs. a) small EVs and cell membrane are differential enriched in lipid moieties. b) composition of inner and outer leaflet of the lipid bilayer surrounding small EVs. Figures adapted from.${ }^{47}$ Legend: PI = phosphatidyl-inositol; PG = phosphatidyl-glycerol; $\mathrm{PC}=$ phosphatidyl-choline; $\mathrm{PC}-\mathrm{O}=$ alkyl-ether substituted phosphatidyl-choline; $\mathrm{PC}-\mathrm{P}=$ alkenylether substituted phospatidyl-choline; $\mathrm{CE}=$ cholesteryl ester; $\mathrm{PE}=$ phosphatidyl-ethanolamine; LPE = lysophosphatidyl-ethanolamine; PE-O = alkyl-ether substituted phosphatidyl-ethanolamine; PE-P $=$ alkenyl-ether substituted phospatidyl-ethanolamine; $\mathrm{Cer}=$ ceramide; $\mathrm{DAG}=$ diacyl-glycerol; GM2 = ganglioside GM2; PA = phosphatidic acid; Gb3 = ceramide trihexoside; GD1 = ganglioside GD1; PS = phosphatidyl-serine; $\mathrm{CHOL}=$ cholesterol; $\mathrm{LPI}=$ lysophosphatidyl-inositol; $\mathrm{SM}=$ sphingomyelin; LacCer = lactosyl-ceramide; GM1 = ganglioside GM1; GM3 = ganglioside GM3; HexCer $=$ hexosyl-ceramide.

\subsection{Lipoproteins}

Lipoproteins are a class of secNPs found in plasma and tissue, whose primary assignment is lipid transport and delivery. ${ }^{48}$ They are nanosized complexes composed by a central hydrophobic core of 
non-polar lipids (Figure 5, bright orange), enveloped in a mono-layered amphiphilic membrane made of phospholipids, cholesterol (Figure 5, blue and green) and apolipoproteins (Apo, Figure 5 grey). Lipid and protein content of a lipoprotein is heterogeneous and evolves during its life and circulation time.

Five classes of lipoproteins exist. Chylomicrons form the biggest and less dense subclass. They are mainly constituted by triacylglycerols and in minor part by phospholipids, cholesterol, and cholesteryl esters and ApoB-48. Chylomicrons are assembled inside enterocytes (intestine cells) during dietary lipids absorption. Chylomicrons avoid liver passage and transport dietary lipids to storage tissues (adipose and skeletal muscles tissues) and to cardiac tissue. After transferring most of triacylglycerol, content they collapse and are up taken and recycled by the liver. ${ }^{49}$ Very LowDensity Lipoproteins (VLDLs) are synthetized by hepatocytes (the liver cells) and are constituted by triacylglycerols and cholesteryl esters assembled with apolipoproteins, preferably ApoB-100. ${ }^{49}$ VLDLs are secreted with a size of $30-80 \mathrm{~nm},{ }^{44}$ but are rapidly degraded by cleaving their fatty acid content into the smaller and denser Low-Density Lipoproteins (LDLs) - note: the transformation passes through the so called Intermediate-Density Lipoproteins (IDL) - VLDLs and LDLs circulate and transport lipids to peripheral tissues, particularly LDL can be up taken by atherosclerotic plaque endothelium (thus representing a high-risk factor) ${ }^{49}$ High density lipoproteins (HDLs) are smaller and denser than LDL, with a diameter below $10 \mathrm{~nm}$, and 1.060-1.200 $\mathrm{gcm}^{-3}$ density. They are enriched in cholesterol and ApoA-I, A-II ApoE and ApoC, and are widely studied due to their protective role against cardiovascular diseases and cardiac acute events. The biosynthesis of HDLs begins with the synthesis of ApoA-I in the liver or intestine. HDLs are then formed through subsequent lipidation of ApoA-I, which gives origin to nascent, discoidal particles. Spherical HDLs are then obtained by internalization of cholesterol esters into the core of HDL particles, a step catalysed by lecithin cholesterol acyltransferase. HDLs remove the excess cholesterol from tissue, that is then transported back to the liver and steroidogenic organs to be recycled ${ }^{49}$ HDLs have the additional peculiarity to also carry other molecules than apolipoproteins and lipids, such as small non-coding genetic materials, mainly micro RNAs (miRNAs) ${ }^{50}$ and other proteins, such as metalloproteinase. ${ }^{51}$ Salient physicochemical properties of lipoproteins are summarized in Figure 5 and Table 1. 


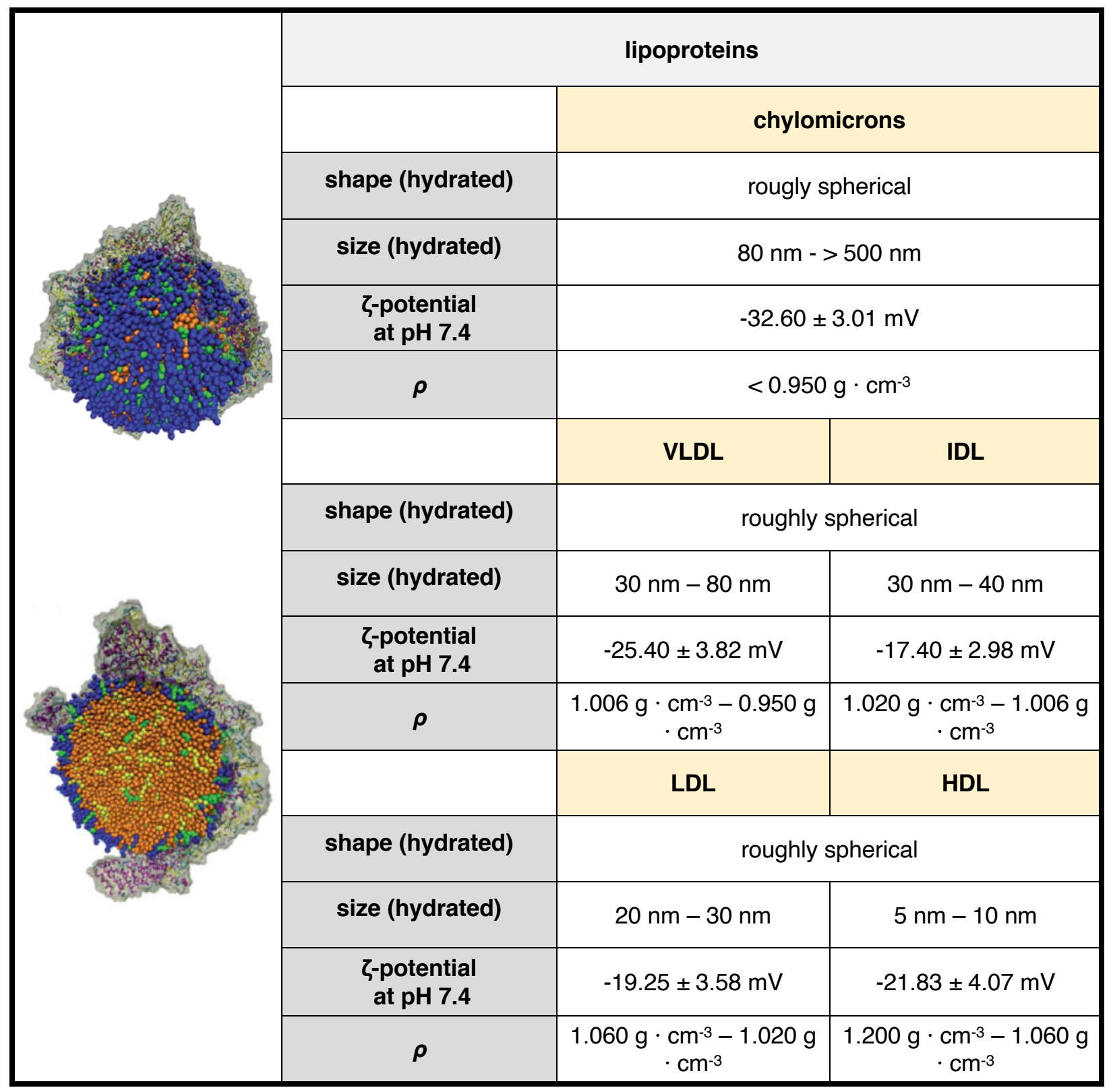

Figure 5. Physicochemical properties of lipoproteins. Chylomicrons $\zeta$-potential is relative to artificial chylomicrons reconstituted via thin layer hydration. Figures adapted and reproduced from ref. ${ }^{52}$ with permission from The Royal Society of Chemistry, copyright 2011. Data obtained from. ${ }^{44,53,54}$ 
Table 1. Lipoprotein components. Composition Table adapted from. ${ }^{55}$

\begin{tabular}{|c|c|c|c|c|c|c|}
\hline \multicolumn{2}{|c|}{} & \multicolumn{2}{c|}{ surface components (mol \%) } & \multicolumn{2}{c|}{$\begin{array}{c}\text { core } \\
\text { lipids (mol \%) }\end{array}$} \\
\hline & $\begin{array}{c}\text { protein } \\
\text { components }\end{array}$ & protein & phospholipid & cholesterol & $\begin{array}{c}\text { cholesterol } \\
\text { ester }\end{array}$ & triglycerides \\
\hline chylomicron & ApoB-48 & 2 & 63 & 35 & 5 & 95 \\
\hline VLDL & ApoB-100 & 2 & 55 & 43 & 24 & 76 \\
\hline LDL & ApoB-100 & 2 & 58 & 42 & 19 & 81 \\
\hline HDL & $\begin{array}{c}\text { ApoA-I, A-II, } \\
\text { E, C }\end{array}$ & 2 & 72 & 23 & 82 & 18 \\
\hline
\end{tabular}




\subsection{Exomeres}

Exomeres are a recently discovered class of secNPs. They are small $(\sim 35 \mathrm{~nm})$, non-membranous particles enriched in specific enzymes and nucleic acids. Exomeres have been firstly separated and characterized by asymmetrical flow field-flow fractionation (AF4). They show unique biophysical features, such as mildly negative $\zeta$-potential and higher stiffness compared to EVs. ${ }^{56}$ Currently, very little is known about exomere traits and biology, except for their ability to shuttle functional, bioactive cargo and to modify the metabolism of recipient cells. ${ }^{57}$

\subsection{Milk proteins, casein micelles and fat globules}

Milk is a mammal gland secretion widely used as processed food product and as primary food for new-born of many animal species. Milk is able to supply not only nutrients through proteins and fatmade nanoparticles, but also regulate immune defence and interact with the gut microbiome. ${ }^{58}$ Milk is an emulsion composed by fat globules, lactose, and soluble proteins mainly caseins (Figure 6a). Triglycerides constitute more than $95 \%$ of the lipids in milk. Fatty acids used for milk fat globule synthesis are derived from the circulating lipids, particularly from chylomicrons and very low-density lipoproteins, or newly synthetized from the mammary gland. ${ }^{59}$ Fat globules are secNPs with a size ranging from hundreds of nanometres to tens of micrometres (Figure 6a). ${ }^{59}$ Fat globules together with lactose and milk proteins originate from epithelial lactating cells that constitute the mammal glands. Fat droplets originate in the cell cytoplasm and are already delimited by a single-layer lipid coat that exists prior secretion. After maturation, lipid droplet moves into cell apical region and buds from plasma membrane acquiring another cellderived external bilayer that is super imposed at secretion and faces directly the surrounding aqueous environment. The multi-layered membrane is functionalized with multiple proteins and mediate the majority of milk fat globules biological effects that are not only related to lipid metabolism but also to the new-born immunitary system and to the intestine physiology (Figure 6b).

Mainly due to their fragile membrane that works as physical interface between their fat content and the surrounding aqueous environment, fat globules are not present in manufactured food products because of the processing temperature, reagents and timings. In fact, to preserve their native structure fat globules requires dedicated separation protocols. Probably for this reason, their therapeutic potential is not yet fully appreciated. ${ }^{60,61}$ 
Caseins are regular components of milks of various species (e.g. cow, goat, rat, mouse and human) and constitute the large majority of proteins in milk. Casein self-assembles to form micelles with a size range of 50 to $250 \mathrm{~nm}$ that contain water, calcium and phosphorous salts, and associated enzymes and exist as colloidal particles (Figure 6a). The specific function and precise internal structure of casein micelles are currently under debate.

a

\begin{tabular}{|c|c|c|}
\hline \multicolumn{3}{|c|}{ milk proteins, casein micelles and fat globules } \\
\hline \multirow{5}{*}{ 政 } & \multicolumn{2}{|c|}{ milk fat globules } \\
\hline & shape (hydrated) & roughly spherical \\
\hline & size (hydrated) & $\begin{array}{l}100 \mathrm{~nm}->1000 \mathrm{~nm} \\
\text { (highly dependent from } \\
\text { extraction protocol and milk } \\
\text { source and processing) }\end{array}$ \\
\hline & $\begin{array}{c}\zeta \text {-potential } \\
\text { at pH } 7.4\end{array}$ & $\begin{array}{c}-9.4 \pm 0.6 \mathrm{mV} \text { (cow milk) } \\
-11 \pm 0.7 \mathrm{mV} \text { (buffalo milk) } \\
-7.9 \pm 0.1 \mathrm{mV} \text { (human milk) }\end{array}$ \\
\hline & $\rho$ & $\sim 0.92 \mathrm{~g} \cdot \mathrm{cm}^{-3}$ \\
\hline \multirow{5}{*}{ of } & \multicolumn{2}{|c|}{ casein micelles } \\
\hline & shape (hydrated) & $\begin{array}{l}\text { roughly spherical, with } \\
\text { submicelles }\end{array}$ \\
\hline & size (hydrated) & $50 \mathrm{~nm}-250 \mathrm{~nm}$ \\
\hline & $\begin{array}{c}\zeta \text {-potential } \\
\text { at pH } 7.4\end{array}$ & $-20.1 \mathrm{mV}$ \\
\hline & $\rho$ & $\sim 1.078 \mathrm{~g} \cdot \mathrm{cm}^{-3}$ \\
\hline
\end{tabular}




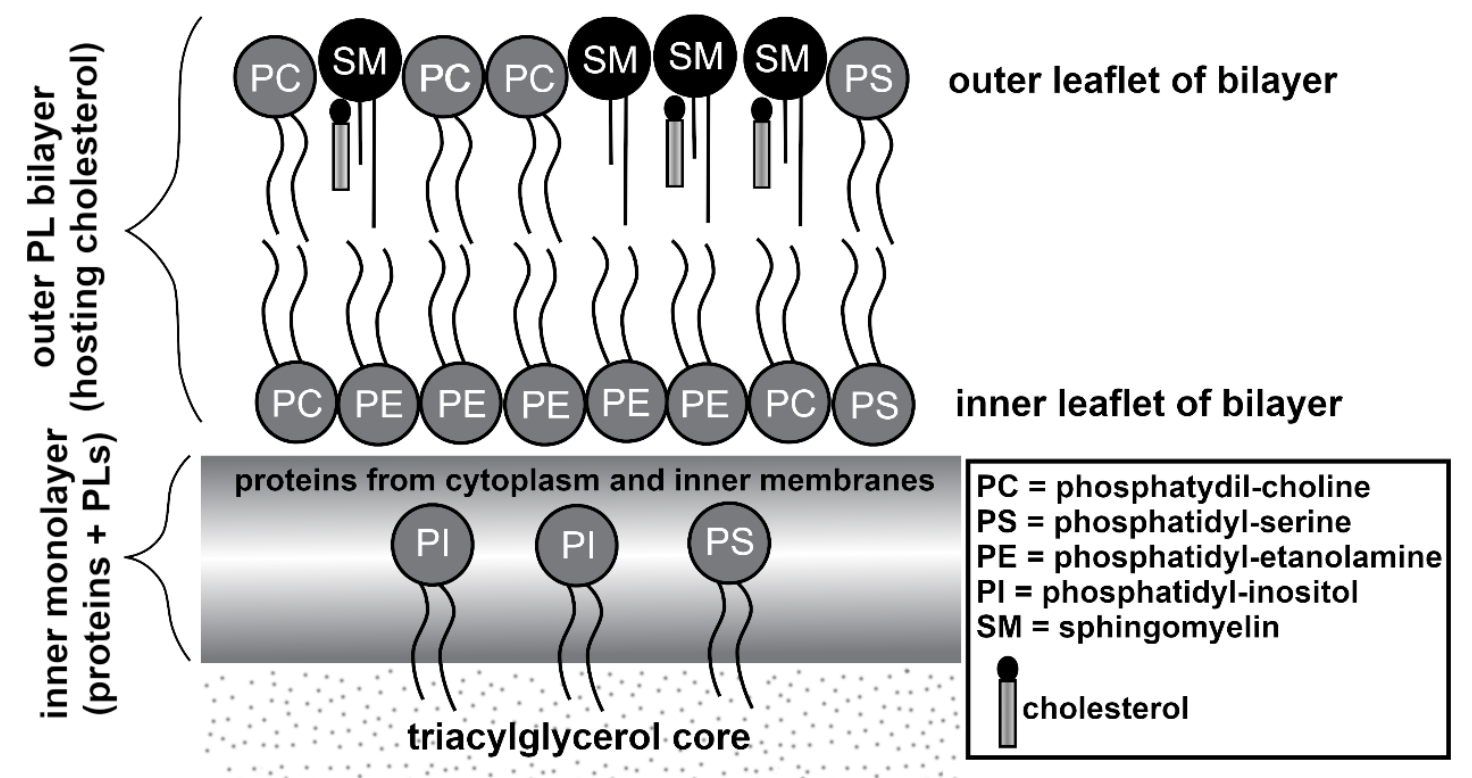

Figure 6. a) Physicochemical properties of milk fat globules and casein micelles. Unknown parameters are here marked as "n.r." (not reported). Please notice that milk fat globule $\zeta$-potential greatly changes in regard to sample homogenization and source. Figures adapted and reproduced from ref. ${ }^{4,6}$, with permission from Elsevier, copyright 2017 and 2019. Data extrapolated from. ${ }^{62-66}$ Legend: $\rho=$ density. b) structure and composition of milk fat globules. Figure adapted and reproduced from ref. ${ }^{67}$, with permission from Elsevier, copyright 2017.

\section{6. secNP zoo: (buoyant) density versus size}

Organizing/visualizing secNP classes and subclasses based on their physicochemical properties may result particularly useful for their rational use, starting from the design of separation protocols (Section 3.1). In Figure 7 we propose as an example the plot obtained by arranging the whole secNP zoo for density versus size. Macromolecular complexes are the densest and smallest, followed by HDL, whose composition is dominated by proteins over lipids. LDLs, VLDLs, and Chylomicrons, which are more and more enriched in lipid content, ${ }^{49}$ follow along the size and density scales. As expected from their composition and structure, all the EV populations are characterized by similar density, shared with the smallest HDL, while their size spans about two orders of magnitude. Milk components instead have a partially overlapping sizes, but different 
densities, which mirrors their composition - proteins for casein micelles, in major part lipids for fat globules -

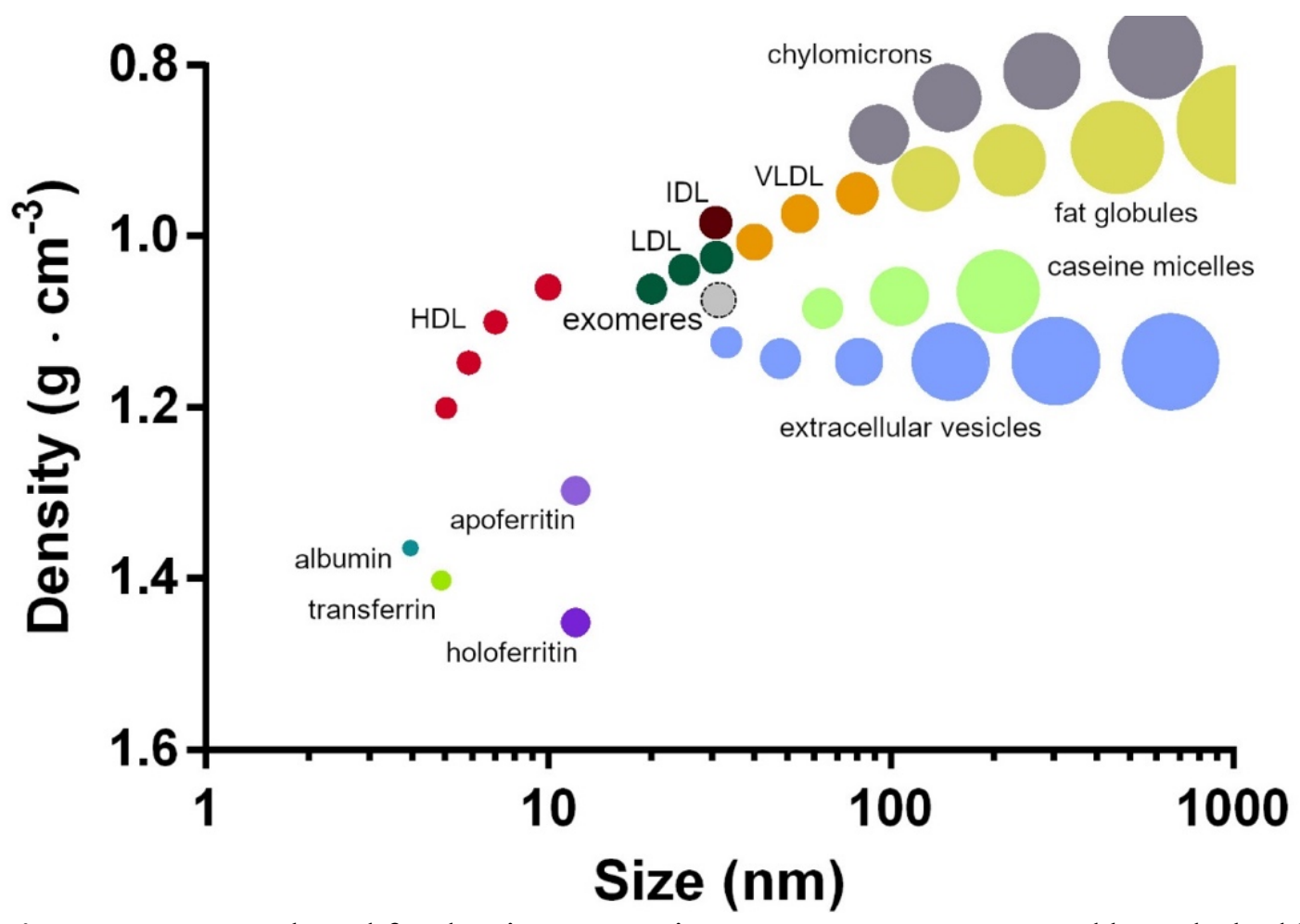

Figure 7. secNPs plotted for density versus size. Exomeres are contoured by a dashed line, since their recent discovery and ongoing physicochemical characterization. The plot was built with the data reported in the previous subsections. It expands to the full set of secNPs the plot proposed by Karimi et al. for EVs and lipoproteins. ${ }^{44}$

\section{Separating, characterizing, tweaking, and engineering}

\subsection{Separation and characterization}

Each SecNP class is characterized by unique features, among which protein/lipid ratio, surface charge, size, and density and is produced through different secretion pathways. Accordingly, native secNPs can be found as mixed constituents of various biological matrices and require dedicated protocols in order to be concentrated or separated. ${ }^{38,49,59,68,69}$ Concentration (or enrichment) aims to collect in small volumes a high number of a given class of secNPs according to one of their distinct physico-chemical properties, such as size or surface charge. Usually, concentration methods allow to process large sample volumes under standardized conditions but conceive the presence inside the 
final formulation of a variable amount of exogenous materials other than solely a specific secNP. ${ }^{70}$ The separation (or purification) of a class of secNPs instead, aims to purely isolate and retain specific secNPs according to two or more chemico-physical distinctive traits. ${ }^{40}$ Usually, separation procedures require time-consuming protocols, frequently characterized by small processable sample volumes and a limited yield. ${ }^{71,72}$ Moreover, an efficient separation is usually hampered by the presence of other classes or subclasses of secNPs inside the starting samples that overlap the chosen secNP in size, density, surface biomarkers etc. ${ }^{71}$

Commonly applied concentration methods exploit secNP size and density (Figure 7) - e.g. ultracentrifugation (UC) and ultrafiltration (UF) - and/or their surface composition and properties e.g. immuno-based separation (IBS) assays and polymer-based precipitation protocols (PPs). ${ }^{73}$ Using UC speeds above or equal to $100,000 \times \mathrm{g}$ for a time dependent on the sample volume at a controlled temperature, is possible to concentrate nanosized material. ${ }^{74}$ However, the high speeds under whom UC is performed affects the stability and integrity of the secNPs, compromising their final number and properties.

UF techniques combine controlled pressure flow with filter membranes designed with pores with a determined size and can be performed following different arrangements. For instance, tangential flow filtration devices apply a flow tangential to the filter obtaining a gentle particle separation able to preserve the integrity of the delicate secNP structure. ${ }^{70}$ Furthermore, UF systems can process large volume of sample under sterile conditions resulting in time saving protocols characterized by considerable secNP yield. ${ }^{70,75,76}$

SecNPs expose specific proteins on their external leaflet and, therefore, are eligible for IBS assays. ${ }^{77}$ IBS usually consists of an immunocapture step, to select secNPs accordingly to the proteins on their surface, followed by a detection method. ${ }^{77}$ IBS applies both regular and secNP-dedicated detectors, mainly flow cytometers, resulting in a highly specific technique able to enrich specific secNP subpopulation. ${ }^{78}$ However, IBS protocols are usually expensive and not scalable to large volumes. ${ }^{78}$ Polymer-based PPs are applied mostly for EVs, OMVs and HDLs. ${ }^{79}$ PPs exploit unspecific interactions between secNPs and synthetic polymers that results in a net that precipitates at lowspeed centrifugation $\left(<5,000 \mathrm{xg}\right.$ ) better preserving the secNP structure. ${ }^{80}$ However, due to the presence of protocol-derived matrix that frequently coprecipitates with the secNPs, PPs highly impact secNPs amount and purity. ${ }^{81}$ Therefore, PPs are usually used to conduct studies about secNP composition instead of in vitro or in vivo functional studies. ${ }^{79,82}$ 
Isolation protocols often combine a first concentration step followed by one or more separation steps based on secNP physical features. ${ }^{83}$ In particular, density gradients and size exclusion chromatography ${ }^{84}$ separate secNPs based on their floating density and size and are usually preceded by UC concentration. ${ }^{81}$ However, in the case secNPs completely overlap in density or size (Figure 7), these methods have the chance to generate a mixed formulation.

Isolation methods, especially if used in combination, ensure a negligible presence of unwanted components inside the final formulations. ${ }^{81}$ However, laborious and time-consuming protocols may compromise both final secNPs structure and yield. ${ }^{85}$ Notably, all isolation methods are known to impact in some extent the final secNP formulation and are difficult to standardize. ${ }^{40,61}$ Therefore, an appropriate approach should be chosen considering volume, number, and evaluability of the starting biological samples, and also based on the next applications envisioned from the study. ${ }^{40,85}$ Even though recently many efforts have been done to introduce and promote guidelines regarding handling and processing of samples, still there are differences in almost all the published scientific literature that hamper the sharing of a common practice. ${ }^{85}$ Microfluidic-based technology represents the latest attempt to combine secNP isolation methods and secNP analysis inside scaled-down devices. Dimension and microfluidics make these devices able to couple high throughput and recovery of secNPs at the nanoscale. ${ }^{86}$

A good isolation practice is always followed by a detailed characterization to confirm the presence of the desired secNPs inside the final formulation. Characterization usually combines imaging, and biochemical techniques and quantification assays to assess secNPs morphology, size, proteinenrichment, and number, respectively. ${ }^{40}$ Morphology and size range can be analysed by highresolution imaging techniques, such as atomic force microscopy ${ }^{81}$ and regular or cryogenic electron microscopy ${ }^{87}$ Size distribution and particle quantification rely on highly sensitive techniques able to detect secNPs physical properties. Specifically, light scattering (nanoparticle tracking analysis, ${ }^{88}$ dynamic light scattering ${ }^{89}$ etc.), electrical sensing based on resistance, ${ }^{90}$ surface plasmon resonance (colorimetric nanoplasmonic assay) $)^{91}$ and fluorescence (fluorescence correlation spectroscopy ${ }^{89}$ and flow cytometry based on micro and nanofluidic). ${ }^{92}$ Protein amount of secNP formulations can be determined with some of the commonly used protein quantification assays, such as bicinchoninic acid, and Coomassie blue assay. In contrast, the detection of specific proteins has to be performed using more sensitive methods, often based on antigen-antibody reactions and able to detect specific proteins enriched on the secNP surface. However, each protein is present at extremely low 
concentrations, requiring a high particle number (usually $>10^{6}$ ) to perform a single analysis with conventional methods, such as western blot, ${ }^{81}$ immunocapture-based flow cytometry ${ }^{93}$ or mass spectrometry ${ }^{94}$. For this reason, in recent years intense effort has been made to improve the

performance of antibody-based techniques, mainly by coupling them to biosensors and microfluidics devices. New analytical platforms include surface plasmon resonance spectroscopy, surface enhanced Raman spectroscopy, micro-nuclear magnetic resonance, nano-plasmonic sensors, integrated magnetic-electrochemical sensors etc. ${ }^{94-96}$

Less commonly characterized components of secNPs are lipids and glycans which can be analysed, for instance, by total reflection Fourier-transform infrared spectroscopy ${ }^{97}$ and high-resolution glycomics, ${ }^{98}$ respectively.

Finally, it is important to emphasize, that all secNPs share at least one physicochemical feature, making univocal separation between classes or subclasses very difficult to achieve. Therefore, a careful characterization of the secNP formulation is fundamental to assess or exclude contamination between subpopulations and to evaluate in which extent it could condition the experimental results. $^{40,44,81}$

\subsection{Tweaking and engineering}

The difference between tweaking and engineering is subtle but important and may be profitably applied for better understanding the plethora of secNP modifications and their intended applications. Cells have been tweaked at the molecular scale for decades. A crucial breakthrough came with the demonstration that an exogenous cDNA deriving from Aequorea Victoria gene, encoding for a green fluorescent protein (GFP), produces a fluorescent product when expressed in prokaryotic $(E$. Coli) or eukaryotic (C. Elegans) cells without the need of substrates or co-factors. ${ }^{99,}{ }^{100}$ We will see that this strategy has been largely applied to produce modified secNPs, which for example overexpress a particular targeting ligand.

Engineering can be instead interpreted as something different: to design the modified secNP in mechanistic detail, with precise knowledge of all the component parts. This may imply the use of various synthetic components and synthesis techniques, which range from the exogenous loading of drug molecules through electroporation to the production of extracellular vesicle by direct cell extrusion. In secNP modification, very often tweaking and engineering overlap and/or combine, ${ }^{101}$ as we will concisely present in the next subsections. 


\subsubsection{Modifying, augmenting and shaking-up}

The widely applied tweaking techniques are intended to produce large amounts of secNPs in a limited range of time with the use of physical or chemical stressors. Variations of cultured cell oxygen level, temperature, $\mathrm{pH}$, and metabolites and direct cells extrusion or incubation with detergents have been reported. ${ }^{102}$ However, secNPs released from cells mechanically or chemically stressed, could not follow classic secretion pathway and not even undergo to a controlled sorting and loading of specific proteins or genetic material into their structure. Therefore, the presence of stressors questions the secNP phenotypes compared to their native counterpart. ${ }^{103}$ Particular consideration should be taken during the evaluation of both structural and functional properties of secNPs produced from stressed and mechanically or chemically disrupted cells.

SecNPs such as lipoproteins, ${ }^{104}$ and casein micelles, ${ }^{105}$ are unique examples of NPs that can be reassembled or synthetized mixing their constitutive components. Synthetic or reconstituted secNPs efficiently mimic physicochemical and biological properties characteristic of native counterparts and have been widely applied and studied mainly as delivery vehicles for molecular therapeutics. ${ }^{104}$ Diverse engineering approaches have been applied to secNPs, in order to produce formulations with known, completed, or enhanced abilities. ${ }^{106}$ The majority of applied engineering strategies aim at the modification of secNPs with organic molecules, such as peptides, antibodies, lipids, and nucleic acids resulting in homogeneous systems with new features improving secNPs translational potential. ${ }^{68,102,106-109}$ Interestingly, secNP chemico-physical properties promote a high-system flexibility opening to different reagents, timings and techniques. Some approaches, usually referred to as endogenous engineering, modify the secreting cells in order to obtain altered secNPs, whereas other strategies called exogenous engineering are based on physico-chemical techniques applied to secNPs after their isolation or during their assembly. SecNPs, mainly nanosized macromolecular complexes, ${ }^{107}$ lipoproteins, and EVs, ${ }^{106}$ are biomaterials suitable to undergo different strategies of passive (incubation) or active (fusion peptides) targeting and passive (mixing) or active (sonication, electroporation, thaw-freezing cycles etc.) drug loading. Ferritin-L-chain (FTL) fused with activator protein 1 (AP-1), resulted in protein-based nanocages targeting interleukin-4 receptor (IL-4R) overexpressing cells. ${ }^{110}$ Notably, engineered ferritin nanocages expressing AP-1 peptides were able to selectively bind IL-4R expressing lung tumor cells blocking the pro-inflammatory pathways activated by IL-4 signalling. ${ }^{110}$ AP-1 ferritin 
nanocages were effective also when tested as treatment for in vivo murine models of induced asthma. Compared to bare ones, AP-1 ferritin nanocages promoted an efficient reduction of inflammation causing an overall inhibitory effect on allergic asthma symptoms. ${ }^{110}$

Active targeting strategies have been applied also to natural LDLs. In particular, engineered LDLs exposing on their surface the transferrin receptor ligand and loaded with chemotherapeutics were used as treatment for brain cancer. ${ }^{111}$ Transferrin receptors are overexpressed in both blood brain barrier (BBB) and brain tumors cells. Therefore, engineered LDLs loaded with chemotherapeutics were able to pass the BBB and accumulate into brain tissue showing a dose-dependent anti-tumor activity towards glioma cells. ${ }^{111}$ Interestingly, gliomabearing mice repeatedly treated with intravenous injection of engineered LDLs showed significant tumor growth inhibition compared to saline, free drug, and native loaded LDLs promoting the highest animal survival rate. ${ }^{111}$

The scientific literature describes a multitude of different approaches intended to manipulate and engineer both eukaryotic and prokaryotic EVs that range from passive or active drug loading, active targeting (see Section 4), click chemistry, and $\mathrm{pH}$ responsive EVs.

EVs have been introduced to click chemistry as it represents a modification technique with limited impact on EV structure and function. EVs were modified using surface chemistry to expose on their outer leaflet proteins functionalized with alkaline groups and successively linked to fluorescent azide molecules. Interestingly, post-modification EVs did not showed any change in size and uptake from parent cells compared to native EVs. ${ }^{112}$

Additionally, Lee et al. designed and produced $\mathrm{pH}$-responsive EVs that efficiently incorporated Dox and hyaluronic acid (HA) grafted with 3-(diethylamino)propylamine (DEAP) into their membrane. In particular, HA mediated the targeting of cancer cells overexpressing cluster of differentiation 44 (CD44), whereas DEAP made EVs responsive to acidic tumor microenvironment. Interestingly, engineered HDEA-EVs exhibited high tumor toxicity both in vitro incubated with cancer cells, and in vivo after intravenous administration in mice bearing subcutaneous colon carcinoma. ${ }^{113}$

Lastly, Chen et al. applied for the first time two separate strategies to obtain simultaneously functionalized OMVs for biosensing and bioimaging. Bacterial cells were genetically modified to express a native E. coli membrane lipoprotein SlyB and a membrane ice nucleation protein (INP) linked to a protein scaffold. ${ }^{6}$ SlyB is naturally exposed into the periplasmic side of 
prokaryotic cell envelope contributing to its stability, whereas INP is a transmembrane protein. SlyB was exploited as a target where to fuse partner protein, namely nanoluciferase (nLuc). INPs instead were linked to multifunctional protein scaffolds ending with antibody binding $\mathrm{Z}$ domains protruding onto prokaryotic cell and OMV surface. SlyB and INP co-expression did not affect the sensitivity of the nLuc nor the antibody constant fraction binding activity of the $\mathrm{Z}$ domain, resulting in customized secNPs suitable for simultaneous bioimaging and biosensing. ${ }^{68}$ Conclusively, the majority of engineering approaches assemble secNPs characterized by enhanced features and able to overcome drawbacks typical of therapeutic small molecules, namely poor stability and affinity. However, there are many hurdles to their translation into clinical nanomedicine due to a lack of protocol standardization and scalability.

\subsubsection{Visualizing and tracking}

The study of secNPs targeting abilities and their possible application as drug delivery vehicles or as regenerative therapeutics (Section 4) requires the investigation of secNP in vivo dynamics, kinetics and distribution.

Ideal in vivo imaging methods should be unequivocally associated to secNP structure, have a high signal-to-noise ratio, and mirror secNP half-life. ${ }^{114}$ To date, different types of molecular imaging techniques have been proposed for a non-invasive secNP tracking ${ }^{68,108,115}$ following both direct and indirect approaches. ${ }^{115}$ Direct labelling techniques entail secNP association with trackable molecules through weak, unspecific bonds or by other loading techniques, namely electroporation and sonication. Indirect labelling instead starts with the modification of the secreting cells in order to obtain secNPs endowed with imaging molecules or NPs. ${ }^{115}$

In particular, fluorescence and bioluminescence are the widely applied techniques to label directly and indirectly secNPs. ${ }^{116}$ Fluorescent lipophilic probes spontaneously intercalate into secNP structure by passive incubation protocols. ${ }^{114}$ However, they require specific post-labelling expedients in order to eliminate unbound fluorescent molecules (washing steps or size exclusion chromatography protocols) that could compromise final EV integrity and yield. ${ }^{114}$ Additionally, lipophilic fluorescent probes can spontaneously dissociate from secNP structure generating unspecific signal not ascribable to EV distribution or uptake. ${ }^{114}$ Other alternative approaches use fluorescent probes that selectively label DNA or RNA shuttled or loaded into EVs, ${ }^{117} \mathrm{HDLs}^{118}$ and 
OMVs. ${ }^{119}$ The main drawback of these labelling techniques is represented by an inadequate sensitivity connected to the limited and varied secNP content of small genetic material and proteins. Bioluminescence is characterized by a high signal/noise ratio since animal tissue do not have any intrinsic bioluminescent activity. ${ }^{116}$ Cells stably transfected with luciferase gene, translate it into a functional bioluminescent reporter protein naturally uploaded into secNPs. ${ }^{116}$

Contrarily to lipoproteins and albumin, EVs and OMVs are characterized by a limited half-life that usually ranges from 30 minutes up to 12 hours. Accordingly, highly stable fluorescent probes that emit signal up to 48-72 hours after their administration are not suitable to give reliable information about EVs and OMVs half-life. In a study published in 2015 by Lai et al., tumor derived EVs were visualized and tracked in vivo using a combination of indirect labelling techniques based on fluorescence and bioluminescence. Secreting cells were simultaneously transfected with two plasmids encoding for Palmtd Tomato fluorescent plasma membrane protein tagged with a repeated sequence binding MS2 RNA and for bacteriophage MS2 coat protein fused with GFP. ${ }^{116}$ This engineering approach allowed to first detect EV budding and mRNA cargo sorting in vitro and to subsequently monitor EVs tumour targeting, mRNA delivery and translation in vivo. ${ }^{116}$ Other secNP labelling techniques use radionucleotides and ultramagnetic NPs. Contrarily to ultramagnetic NPs, radionucleotides benefits from high in vivo sensitivity given by the tissue permeability of gamma rays. However, radionucleotides are expensive, difficult to handle and require dedicated detection systems. Keila et al., used reconstituted HDLs (rHDLs) as carriers for radio-imaging agents. Given the high demand of cholesterol for membrane synthesis, tumor cells frequently overexpress SR-B1 receptors that mediate rHDL uptake. Therefore, rHDLs loaded with a modified hydrophobic radio pharmaceutical have been used as vehicles to target SR-B1 overexpressing cancer cells. ${ }^{120}$ Interestingly, rHDL loaded with hydrophobic radio-imaging agents retained intrinsic tumor targeting properties both in vitro and in vivo, exhibiting great potential as a radiopharmaceutical transporter for the imaging and diagnosis of SR-B1 overexpressing tumors. ${ }^{120}$

\section{Clinical opportunities}

\subsection{Drug delivery}

Drug delivery nanoscale vehicles able to reach and accumulate into the target site without damaging other organs promise to significantly improve treatment results and patient outcome. After two decades of intense efforts and funding, the use of inorganic NPs for the task has been recently 
severely questioned, with reasons which include low circulating stability, poor targeting ability and toxicity. ${ }^{121}$ Accordingly, the advancement of synthetic NPs to the clinic has been far below expectations. $^{122}$

Contrarily, since their discovery all the classes of secNPs, mainly lipoproteins and EVs, have been envisioned as natural delivery vehicles for molecular therapeutics. In fact, secNPs are inherently provided with superior biological/biomedical properties compared to even the most advanced synthetic NPs, including improved targeting, and circulation performance combined to increased bioavailability, personalization and sustainability. The state of the art in this particular field, which also takes advantage of several tweaking and engineering strategies outlined in Section 3.2, will be summarized in the following subsections.

Noteworthy, Table 2 lists some review papers that discuss techniques, applications, and future perspectives of secNPs as drug delivery vehicles.

\subsubsection{Nanosized macromolecular complexes}

The use of both bare and coated nanosized macromolecular complexes for targeted drug delivery purposes is largely reported. ${ }^{17,123-125}$ Circulating proteins are highly uptaken by cancer cells through the overexpression of specific surface receptors. Therefore, globular transport proteins often result in biological NPs with intrinsic tumor-targeting abilities. ${ }^{126}$

One of the first example of clinically approved NPs for cancer treatment is represented by Abraxane that consists in albumin bound to paclitaxel through hydrophobic chemical interactions. However, after systemic administration albumin and paclitaxel dissociate after a short circulation time entailing limited therapeutic effects.

In order to overcome these limitations, endogenous albumin has been engineered by using active targeting strategies and re-arranging it into nanosized macromolecular complexes with enhanced stability and targeting abilities. Particularly, albumin-based macromolecular complexes used to treat tumor-bearing mice resulted in enhanced antitumor effect, and limited off-target delivery to secondary organs. ${ }^{126}$

Globular nanosized proteins were exploited also as biogenic vehicles for therapeutic molecules, such as doxorubicin, that if systemically administered cause multiple long-term side effects. Apoferritin-based NPs functionalized with antibodies against prostate specific membrane antigens and loaded with doxorubicin (APOFe-Dox- $\alpha$ ) have been applied as drug delivery vehicles for 
prostatic cancer treatment. ${ }^{127}$ Notably, APOFe-Dox- $\alpha$ active targeting mediated a tumor specific drug delivery both in vitro and in vivo in mice bearing subcutaneous xenografts of human prostatic cancer cells. ${ }^{127}$ Specifically, APOFe-Dox- $\alpha$ targeted and accumulated into subcutaneous prostatic tumor showing a negligible liver, kidney and heart uptake, thus reducing Dox-mediated toxicity to secondary organs. ${ }^{127}$

Ago proteins are largely known to bind and mediate the intercellular transfer of hydrophobic and

poorly stable non-coding genetic material, specifically silencing RNAs (siRNAs) and miRNAs. ${ }^{125}$ siRNAs regulate cell metabolism through gene silencing and recently emerged as novel therapeutic strategy for a broad range of life-threatening pathologies. However, siRNA application is severely hampered by their poor stability. Interestingly, Ago2 and siRNA complexes coated with cationic polymers resulted in stabile platforms able to perform gene silencing both in vitro and in vivo. ${ }^{128}$ Cationic polymers not only improved Ago2-siRNA complex stability but mediated also an efficient endo-lysosomal escape that resulted in enhanced gene silencing. Accordingly, Ago2-siRNA NPs coated with polyamines caused a significant tumor growth inhibition in melanoma mouse models increasing their survival rate. ${ }^{128}$

\subsubsection{Extracellular Vesicles}

EVs represent the classes of secNPs that have been most widely studied for drug-delivery purposes. ${ }^{129-132}$ The heterogeneity of EV structure makes them suitable for the loading of different cargoes, including chemotherapeutics, ${ }^{133}$ non-coding RNAs, ${ }^{134}$ synthetic nanoparticles, ${ }^{135}$ and oncolytic viruses. ${ }^{136,137}$

One among the first pioneering papers proposing EVs as vehicles for therapeutic siRNAs was published in 2011 by Alvarez Erviti et al. They produced and isolated engineered EVs exposing a brain-targeting fusion peptide on their surface and successively loaded with a siRNA targeting a gene involved in Alzheimer's pathogenesis. ${ }^{138}$ Notably, engineered and loaded EVs intravenously injected in mouse models were able to efficiently silence target gene expression in different brain areas, proving their efficacy as therapeutic vehicles. ${ }^{138}$

Because EVs offer portion of native cell membrane, they often provide better targeting both in vitro and in vivo compared to soluble nanosized macromolecular complexes. For example, engineered ferritin nanocages and EVs resulted in different tumor targeting efficiency mainly due to structural differences. Ferritin NPs and EVs displaying tumor targeting ligands on their surface were able to 
bind to cancer cells avoiding their interaction with phagocytes and consequently blocking the harmful crosstalk between tumor and immune cells. However, if compared with ferritin NPs, EVs resulted in an improved binding to cultured cancer cells in vitro inducing an efficient immunemediated antitumor response. ${ }^{139}$ Accordingly, EVs showed a significantly impaired and delayed tumor growth also in vivo when applied as treatment for subcutaneous colon adenocarcinoma in both immunocompromised and immunocompetent mice. ${ }^{139}$

Lately, EVs isolated from mouse blood and loaded with dopamine (dopEVs) have been studied as treatment for Parkinson's disease. ${ }^{140}$ Interestingly, in this work no pre- or post-isolation engineering strategy was applied to EVs. In fact, transferrin - an abundant blood protein often associated to the structure of blood EVs - directly mediated EV passage across the BBB. ${ }^{140}$ DopEVs associated to transferrin molecules were used as treatment in murine models of Parkinson's disease, resulting in the delivery of high quantity of dop into mouse brain, striatum, and substantia nigra and in an overall pathological phenotype improvement. ${ }^{140}$

OMVs work as natural nanocarriers for highly immunogenic antigens, such as membraneassociated proteins and proteinaceous virulence factors that induce a systemic immune-protection against pathogens ${ }^{43}$ (see Section 4.2). OMVs offer also an effective support structure for enzyme immobilization or transportation. Particularly, OMVs enzyme immobilization is naturally modulated by bacterial metabolism, outperforming in quality and efficiency conventional artificial methods based on resins. ${ }^{43}$

\subsubsection{Lipoproteins}

Due to their natural role as lipid-transporter, lipoproteins are tunable as carriers for other hydrophobic molecules and small non-coding genetic material. ${ }^{108,141,142}$ Furthermore, lipoproteins escape any interaction with the immunitary system and are actively uptaken from target cells following a ligand-receptor pathway. Ultimately, lipoproteins represent a heterogeneous class of safe, biocompatible, biodegradable, non-immunogenic drug carriers. ${ }^{108,141}$ Recently, chitosan NPs loaded with Dox and functionalized with LDLs encasing therapeutic siRNA have been applied for the treatment of multidrug resistant liver cancer. LDL-based chitosan NPs successfully combined the stability of chitosan NPs and the targeting ability of LDLs exhibiting a dose-dependent and cytotoxicity towards Dox resistant liver cancer cell line and an effective gene silencing. ${ }^{143}$ Furthermore, LDL-based chitosan NPs efficiently escaped immunitary system 
clearance and accumulated into subcutaneous hepatic tumors, avoiding healthy hepatic tissue, and reducing multi-drug resistant hepatic cancer growth. ${ }^{143}$

HDLs are actively uptaken by cells through scavenger receptor class B type 1 (SR-BI) proteins which are typically overexpressed in hepatocytes and some types of cancer cells. Due to their physical properties and functional role (see Section 2.2 and Figure 3), native or rHDLs have been conceived as carriers of small molecular therapeutics and siRNAs for the treatment and prevention of atherosclerosis and tumors. rHDLs loaded with siRNAs targeting Pokemon proto-oncogene (siRNA-HDLs), resulted in stable complexes applicable as treatment of human hepatocellular carcinoma. ${ }^{144}$ Notably, siRNA-HDLs efficiently targeted cancer cells resulting in a negligible cytotoxicity in vitro, and a time-dependent antitumor response in vivo achieved through Pokemon gene transcription inhibition. ${ }^{144}$

Considering natural plasmatic HDLs, they can be isolated and engineered with ligands mediating both active targeting and transport. For example, engineered HDLs loaded with chemotherapeutics and exposing on their surface a transferrin receptor ligand and a glioma-homing peptide were able to overcome BBB and target glioma tumors. ${ }^{145}$ Particularly, HDLs engineered with the transferrin receptor ligand were able to overcome BBB causing the highest animal survival time compared to HDLs engineered with glioma targeting peptide alone, bare HDLs, free drug, and saline. In conclusion, both natural and reconstituted lipoproteins alone or coupled with other NPs are suitable as stable carriers for small molecules, among which hydrophobic chemotherapeutics and siRNAs, resulting in a targeted intratumoral delivery. ${ }^{144}$ To the best of our knowledge, the application of chylomicrons and VLDL as drug-delivery vehicles has been overlooked.

\subsubsection{Milk Proteins, casein micelles and Fat Globules}

In milk, casein spontaneously assembles into hollow secNPs with a hydrophobic core. Therefore, casein micelles are particularly envisioned for drug delivery applications. ${ }^{146}$ However, due to change of the fluid phase, after systemic administration casein NPs often disassemble. ${ }^{147}$ Several techniques have been used to build more stable crosslinked casein micelles. Recently, casein micelles linked using glyceraldehyde and loaded with hydrophobic molecules have been tested as drug delivery vehicles in vitro. ${ }^{147}$ These casein NPs showed a controlled degradation under simulated intra-lysosomal conditions; once suspended in neutral $(\mathrm{pH}=7.4)$ or acidic buffer $(\mathrm{pH}=5)$ casein micelles underwent to mild or significant degradation, respectively. Furthermore, their 
structure was completely destroyed in presence of proteases like trypsin. ${ }^{147}$ Conclusively, stable crosslinked casein micelles could survive to blood circulation conditions but can be completely disassembled by lysosomal conditions with a consequent time-dependent release of their cargo. This make them suitable carriers for intracellular delivery of hydrophobic molecules, such as anticancer therapeutics. ${ }^{147}$

To the best of our knowledge, the application of milk fat globules as drug delivery vehicles has so far been overlooked.

\subsection{Vaccines}

Vaccines represent one of the greatest successes of modern medicine for reducing infectious disease and are estimated to save millions of lives globally each year. Nevertheless, many diseases are not yet preventable by vaccination and some current vaccines could be improved for high efficacy and safety. This large unmet medical need demands further research which has already succeeded in developing modern vaccines. Compared to the 19 th and early 20 th century vaccines that were made of killed, inactivated, or live-attenuated pathogens, modern vaccines contain isolated, highly purified antigenic protein subunits which are safer but tend to induce lower levels of immunization. An effective way to address these limitations has gradually emerged through studies of structural vaccinology and nanoparticle research by developing antigen nanoparticles, which can mediate multi-copy antigen display, thereby mimicking the repetitive surface architecture of a natural microbe. ${ }^{148}$ Please refer to Table 2 to find examples of scientific literature discussing the application of the different subclasses of secNPs for immunostimulatory purposes.

\subsubsection{Nanosized macromolecular complexes}

Many naturally occurring proteins can self-assemble into nanoparticles that optimally interact with various cells of the immune system.

Among those, Albumin (used for years as a stabilizer in different vaccine formulations) has been recently employed in the development of novel vaccine nanocomplexes. By conjugating specific antigens with Evans blue (EB) into albumin-binding vaccines (AlbiVax), Zhu et al. developed clinically promising albumin/AlbiVax nano-complexes that self-assemble in vivo from AlbiVax and endogenous albumin for efficient vaccine delivery and potent cancer immunotherapy. ${ }^{149}$ 
Ferritin self-assembles into nanoparticles with robust thermal and chemical stability that are potentially suited to carry and expose immunogens. As an example, a ferritin nanocage-based influenza vaccine has been developed in an eukaryotic cell and could elicit broad neutralizing antibodies against a variety of influenza viruses. ${ }^{150}$ A ferritin-based peptide epitope display system has also been successfully developed in prokaryotic cells gaining 100\% passive protection rate after the immunization ${ }^{151}$ Ferritin nanoparticles have finally been applied in personalized tumor immunotherapy by building a SpyTag/SpyCatcher-enabled click vaccine platform. ${ }^{152}$

\subsubsection{Extracellular Vesicles}

OMVs, due to their intrinsic immunogenicity combined to the capacity to deliver carriers and inherent adjuvants, have a great potential as vaccine platforms. ${ }^{153}$ Many successful experiments have led to the development of OMVs with proven safety and immune stimulating activities that could be employed as tools in prophylaxis applications. E. coli derived OMVs have been combined with malarial proteins in the development of an intranasal vaccine, which promoted an immune response comparable to the one promoted by cholera toxin adjuvant. Interestingly, OMVs are compatible with different vaccine platforms and were found to stimulate both cellular immunity and humoral immune response, thus possessing comprehensive immune reactivity.

Major limits about OMV application in vivo concern about their safety and post-administration stability. Therefore, ongoing investigations are aimed to discover their compositions and alter their contents to improve those issues. ${ }^{43,154}$

Apart from OMVs, also EVs from other pathogens as helminths can potentially elicit an immune response due to high immunogenicity of EV proteins. Different research approaches are gathering information about helminth EV composition for their future exploitation as vaccines. ${ }^{155}$ Finally, also EVs isolated from animals previously infected with viruses, (e.g porcine respiratory and reproductive virus) containing viral proteins but free of virus particles can be recognized by the immune system and represent an alternative vaccination strategy. ${ }^{156}$ 


\subsubsection{Lipoproteins}

Small discoidal HDLs are nanoparticles with a long half-life in plasma, therefore they have been utilized for the delivery of a variety of small lipophilic or amphiphilic molecules. By incorporation of various chemotherapeutic drugs as payloads into synthetic HDLs, also called nanodiscs, Kadiyala et al. induced tumor regression and long lasting anti-GBM immunological memory through a chemo-immunotherapy mediated mechanism. ${ }^{157}$ Nano-discs that can co-deliver multiple adjuvants (e.g. a TLR4 agonist MPLA, and a TLR9 agonist CpG) have also been developed. Those systems effectively activate dendritic cells by upregulating costimulatory signals and inducing proinflammatory cytokines, compared with free adjuvants and may provide a powerful delivery platform for vaccine applications against cancer, infectious diseases, and other pathologies. ${ }^{158}$ Finally, LDLs, conjugated with Fluorescent ovalbumin (OVA) and lactobionic acid resulted in a substantially increased uptake of OVA by murine macrophage-like ANA1 cells, and by primary peritoneal macrophages due to uptake by G-protein coupled receptor. This antigen delivery system could be used as an alternative way of delivering drug or vaccine directly to macrophages.

\subsubsection{Milk proteins, Casein Micelles and Fat Globules}

Some vaccines could contain hidden milk proteins, in order to prevent virus degradation. But none of those has been used in purpose to elicit immunogenic activity.

\subsection{Regenerative therapeutics}

Regenerative medicine takes advantage of the capability of stem cells to induce repair pathways into damaged tissues and diseased organs. Since the advent of the first cell-based regenerative techniques, significant progresses have been made and several therapies have begun to enter the clinic. Many stem cell-secreted secNPs exhibit a restorative potential comparable to parental cells, laying the groundwork for cell-free therapeutics. This approach presents considerably lower risks in regard to their cell-based counterparts (e.g. neoplastic transformation, poor immune compatibility, difficulties in handling and storage). 


\subsubsection{Nanosized macromolecular complexes}

Applications of secreted nanocarriers in regenerative medicine are scarcely reported, except for albumin. Examples are given in the following, while extended information can be found in. ${ }^{159}$ Albumin possesses features that fall outside its transport duties. Findings suggest that albumin has an active role in bone proliferation, although a precise mechanism has not been identified. Therefore, several studies examined albumin employment in regenerative medicine, especially in bone reconstruction. Albumin coating enhances mesenchymal stem cells adhesion, proliferation and long term survival in bone allografts, which have been successfully used in human bone reconstruction. ${ }^{160}$ Bone allografts represent a good alternative to autologous bone, which has excellent regenerative properties but suffers drawbacks, such as the scarce availability and donor site morbidity. On the other hand, standard allografts present less osteogenic and osteoinductive properties, due to destruction of bone cells and denaturation of proteins occurring during scaffold preparation. Functionalization with albumin led to the creation of more performant allografts: for instance, albumin-doped bone allografts lead to faster and better outcomes in patients undergone to anterior cruciate ligament reconstruction. ${ }^{160}$ The same research group functionalized suture materials with albumin, creating bio-active sutures for surgical stem cell transplantation. ${ }^{161}$ In this case, albumin was freeze-dried on the surface of polyfilament absorbable thread, which was subsequently seeded with rat bone marrow mesenchymal stem cells and used to unite the wound edges sliced in a rat triceps. Suture-transplanted stem cells maintained their vitality after surgery and readily migrated in the damaged tissue, supporting the regenerative process.

\subsubsection{Extracellular Vesicles}

This section is entirely focused on eukaryotic EVs, since the use of prokaryotic OMVs in regenerative medicine is currently not documented. Eukaryotic stem cell regenerative potential derives from the secretion of many soluble and nanostructured factors that naturally promote healing, rather than their engraftment and proliferation in damaged tissue. EVs represent a consistent part of the rich secretome of stem cells. Thus, stem cell EVs are a promising tool for regenerative purpose, since they mimic part of the biological tasks of stem cells, particularly the ones responsible of tissue maintenance and repair. Few examples are given in the following, while a comprehensive dissertation can be found in. ${ }^{162}$

MSC-EVs exert their action through the delivery of encapsulated bioactive molecules (including 
enzymes and various non-coding RNAs) to the cells of tissue microenvironment, modulating many signalling pathways. Indeed, MSC-EV cargo is functionally complex and comprise molecules involved in regulation of metabolism, angiogenesis, inflammation and others. As a direct result, MSC-EVs have been successfully employed in cell-free treatment of many injury models. For instance, EVs produced by hypoxic MSCs ameliorated the conditions of APP/PS1 mice, an Alzheimer's disease model ${ }^{163}$. After systemic administration of EVs, mice showed reduced levels of $\beta$-amyloid and deposition of $A \beta$ plaques in brain, reduced activation of pro-inflammatory pathways of STAT3 and NF-kb. Moreover, mice exhibited lower expression of pro-inflammatory cytokines IL-1 $\beta$ and TNF- $\alpha$ and higher expression of anti-inflammatory molecules, such as IL-4 and IL-10, in brain tissue. An overall improvement of cognition and memory was also observed. Beneficial effects were ascribable to the raising of brain levels of miR-21, a small non-coding nucleic acid known to be directly involved in the downregulation of inflammation processes. Similar results were obtained in peripheral nerves injury animal models. Ma et al. ${ }^{164}$ observed motor function restoration in rats, after sciatic nerve transection. Systemic injection of EVs produced by human umbilical cord MSC (hUCMSC-EVs) promoted extensive Schwann cell growth, axonal regeneration and myelination, and consequently reduced muscular atrophy. Interestingly, near the site of injury the aggregation of hUCMSC-EVs was observed, suggesting that hUCMSC-EVs promoted nerve regeneration establishing a favourable environment for tissue reconstruction. In particular, hUCMSC-EVs locally lowered the expression of pro-inflammatory molecules, in a similar way observed also by Cui et al. ${ }^{163}$ Many other organs were treated with MSC-EVs (e.g. skin, cartilage, liver and lung), highlighting their broad spectrum of healing modalities. Few ongoing early clinical trials are testing the regenerative potential of MSC-EVs in patients with acute ischemic stroke (NCT03384433), intractable cutaneous ulcers (NCT02565264) and large eye macular holes (NCT03437759).

Notably, MSCs represent the most common but not the exclusive source of staminal EVs. Indeed, even induced pluripotent stem cells, ${ }^{165}$ cardiac, ${ }^{166}$ amniotic fluid, ${ }^{167}$ and embryonic ${ }^{168}$ stem cells release EVs. It is likely that other stem cell EVs operate on the injured tissue in the very same way MSC-EVs do. Although the use of natural, unmodified EVs is prominent in regenerative medicine, few examples of stem cells and non-stem cells EV engineering are reported in literature. Such approaches are mainly intended to enhance natural EV healing properties by loading EVs with endogenous molecules, or by augmenting EV targeting 
capabilities by means of surface modifications. For instance, Vandergriff et al. decorated cardiac-stem cell derived EVs using a cardiac homing peptide and tested them in a mice model of heart ischemic/reperfusion injury. Such modification allows to circumvent dangerous EV intracardiac injections in favour of more safe EV intravenous administrations with a minimal loss of treatment efficacy and negligible off-target effects. In vitro, ex vivo and in vivo experiments were performed, pointing out that engineered cardiac-stem cells derived EVs truly possess infarct-targeting features and regenerative potential: indeed, hearts of treated mice showed lowered cardiac fibrosis and enhanced cell proliferation and angiogenesis if compared to control animals. Finally, it is worth noticing that EV engineering specifically intended for regenerative purposes is to date far less represented than in other topics (e.g. cancer, neurodegenerative disorders etc.), suggesting that this field is still in its infancy.

\subsubsection{Lipoproteins}

So far, HDLs are the only lipoprotein subclass that has been investigated in regenerative medicine. HDLs remove the excess of lipids and cholesterol from peripheral tissues and transport them to the liver for catabolism and excretion. Many studies attest the protective role of HDLs; indeed, such secNPs possess anti-inflammatory, anti-oxidative, anti-apoptotic and pro-angiogenetic properties, and have been recognized as possible therapeutics for cardiovascular diseases. HDL beneficial effects seem to be linked to the activation of specific molecular pathways by two macromolecular components: ApoA- $\mathrm{I}^{169}$ and sphingosine 1 phospate. ${ }^{170}$ To date, two main strategies were tested in vitro and in vivo to prove HDL efficacy: direct injection and topic application of HDLs. Examples are given in the following, while general information about the protective and regenerative roles of HDL can be found in. ${ }^{171,172}$

HDLs reduce palmitate-induced apoptosis in cardiomyocytes. ${ }^{173}$ Palmitate cause lipotoxicity via downregulation of AMP-activated protein kinase (AMPK). HDL treatment of palmitate-fed cardiomyocytes resulted in the improvement of several pro-apoptotic parameters (e.g. Annexin-V levels and $\mathrm{Bcl} 2 / \mathrm{Bax}$ ratio), and in enhanced expression of genes involved in cell contractility and fatty acid oxidation. Interestingly, such genes are under the control of AMPK-dependent pathways. ${ }^{173}$ Thus, HDLs are effective contrasting lipoapoptosis caused by the accumulation of free fatty acids in cells or organs (steatosis). Steatosis of non-adipose tissue is typical in patients affected by metabolic syndrome and obesity. HDLs could be implemented as a treatment for such 
conditions, aside traditional approaches (e.g. physical exercise, anti-steatotic drugs, calories fastening etc.). However, in clinics, application of natural HDLs is clearly limited. Synthetic rHDLs (see section 4.1.3 for further details) are used instead. ${ }^{174}$ rHDLs have been tested in vitro and in vivo, and their benefits resemble almost perfectly natural HDL ones. ${ }^{175-177}$ For instance, in ${ }^{176}$ C57BL/6N mice were fed with coconut oil (CC) diet for 6 months, in order to cause heart dysfunction. High fat feeding induced several cardiac impairments, such as ventricular hypertrophy, increased interstitial fibrosis, decreased stroke volume and lower capillary density compared to control mice (which were fed with standard diet). Strikingly, periodic intraperitoneal administration of rHDL ( 8 infusions, with an interval of $48 \mathrm{~h}$ ) after CC diet reversed pathological heart remodelling occurred in mice and restored cardiac function to normality. Moreover, the treatment had no side effects on healthy control mice. It is worth to notice that rHDL formulation used on this study was based on the so called "Milano" isoform of Apo-A1, a mutated variant of Apo-A which present enhanced activity in regard to wild type form. Current clinical trials are testing Milano Apo-A1 efficacy in the treatment of cardiovascular diseases (e.g NCT02678923).

\subsubsection{Milk proteins, Casein Micelles and Fat Globules}

Currently, there is no evidence that fat milk proteins, casein micelles and fat globules could be potentially applied in regenerative medicine. However, Lactoferrin, an iron-binding protein that is mainly - but not exclusively - found in milk, have been successfully adopted in animal bone reconstruction. ${ }^{178}$

\subsection{Diagnostics}

Biomarkers in both basic, and clinical research and clinical practice are to date necessary to monitor physiology as well as disease onset. Indeed, parameters with high predictive and prognostic value are mandatory to define therapy effectiveness and clinical outcomes. The nanostructured secretome represents an immense, easily accessible reservoir of such information. SecNPs are inherently multiplexed and very sensible to changes occurring during disease onset and evolution. Some of the secNPs treated in the present section are long-established biomarkers, and their use is well documented. Other categories of secNPs are not yet implemented in clinics but conceal great potential. 


\subsubsection{Nanosized macromolecular complexes}

Nanosized macromolecular complexes are the most accessible, well-established biomarkers which are routinely used to outline the general health condition of an individual. However, multiplexed biomarkers are, by their own definition, a source of multiple parameters, whose alteration is linked to one or more pathological conditions onset. Since most of nanosized macromolecular complexes are tested for just one parameter (which usually is the titer), they cannot be fully considered multiplexed biomarkers, and therefore are not discussed. An exception is made for Ago proteins, ${ }^{22}$ a subset of secNPs specialized in the transport of RNAs, including miRNAs, Piwi-interacting (piRNAs) and transfer RNA (tRNA) fragments. Circulating RNAs, especially miRNAs, recently arose as key players in post-transcriptional regulation of protein expression. Ago proteins are normally localized in cytoplasm, as functional part of the RNA-Induced Silencing Complex (RISC, involved in RNA silencing and interference), but presence of circulating isoforms (e.g. Ago2) is reported. ${ }^{179}$ Whether Ago proteins are released in soluble form, inside transporters such as EVs, or in both conditions is still matter of debate. To date, a plethora of clinical studies correlate specific 'circulating RNA signatures' to certain pathologies (pancreatic cancer, ${ }^{180}$ sarcomas, ${ }^{181}$ and many others), or link them to differential therapy response, ${ }^{182-184}$ fostering Ago proteins and their cargo as powerful biomarkers. For instance, Asano and co-workers ${ }^{181}$ analysed more than 1000 samples coming from patients affected by soft tissue and bone tumors (comprising sarcomas, intermediate tumors and benign tumors) and developed a molecular panel of seven circulating miRNAs, able to discriminate malignant from benign tumors and healthy controls. Another example of Ago2-bound miRNA potential is given by Fuji et al. ${ }^{179}$, who identified two miRNAs in serum of patients affected by colorectal cancer (CRC). Mir-21 and mir-200c revealed to be valuable tools to assess CRC insurgence and response to chemotherapy. Authors claim that mir-21 is mainly released into bloodstream through active export by cancer cells, therefore it can be used to distinguish CRC patients from healthy controls. On the contrary, mir-200c is a cytoplasmic miRNA, and its presence in serum is attributable to cytolysis caused by drugs. Consequently, fluctuations in mir200c levels are inversely linked to tumor response during chemotherapy. 


\subsubsection{Extracellular Vesicles}

Extracellular Vesicles shuttle bioactive proteins, carbohydrates and nucleic acids throughout the body, shielding their cargo within a lipid bilayer. Research in the eukaryotic EV-field is thriving, enumerating such secNPs as one of the most promising source of disease biomarkers by means of fluid biopsy. The topic is already debated in many general and specialized review; ${ }^{7,185,186}$ and a brief outline is given in the following. On the contrary, prokaryotic OMVs have no current use in biomarker discovery. Nevertheless, their future use cannot be excluded, especially in infectious diseases. EVs provide two different sources of information: molecular and biophysical. Molecular information is denoted by EV structural components and cargo; biophysical information is instead represented by EV colloidal properties. To date, biomarker discovery has been largely focused on the molecular/compositional aspects of EVs. Indeed, several miRNAs and proteins have been recognized as specific for cancer and non-cancer-related disease ${ }^{187}$ of many organs, including, but not limited to, kidney, ${ }^{188}$ liver, ${ }^{189}$ lung, ${ }^{190}$ brain, ${ }^{40}$ pancreas, ${ }^{191}$ and prostate. ${ }^{192}$ For instance, Li et al. captured prostate derived EVs from cell medium and urine using an innovative superparamagnetic nanoparticle-based sensor able to bind a specific prostate membrane antigen, using aptamers. The assay allows for detection of extremely low quantity of prostate EVs in solution ( 100 particles $/ \mu \mathrm{L})$, thanks to quantification of ssDNA probes bound to aptamers. ${ }^{193}$ Such probes are displaced whenever aptamers bind EVs, allowing for their amplification. Thus, probe displacement and amplification provide an indirect quantification of captured EVs. Moreover, EV binding to aptamer is reversible, allowing for the recovery of intact EVs for further analysis (e.g. detection of prostate cancer antigens, such as PSA or PCA3 mRNA). Together with breakthrough in diagnosis, the variegated set of molecular markers transported by EVs offer clues about disease nature and may constitute a tool to monitor its evolution over time. Recent oncological studies have shown that EVs provide information on tumor heterogeneity and mutations. Such information can be key for many aspects, including treatment guidance, drug resistance monitoring and prognosis. For instance, Reátegui et al. ${ }^{194}$ identified a mutated form of EGFRvIII mRNA inside tumor-derived EVs extracted from serum and plasma of patients affected by glioblastoma multiforme (GBM). Interestingly, such form of mRNA translates in a mutated form of EGFRvIII containing a tumor-specific epitope recognized by antibodies and T-Cells, making the tumor susceptible to immunotherapy. Shao et al. ${ }^{195}$ gave an important example on how circulating EVs can be used to monitor therapy response. In their 
study, they showed the relation between GBM drug resistance and the levels of O(6)methylguanine DNA methyltransferase (MGMT) and alkylpurine-DNA-N-glycosylase (APNG) mRNAs carried by blood EVs.

$\mathrm{EV}$ molecular content is fostered as diagnostic and prognostic tool also for non-cancer diseases, such as auto-immune ${ }^{187}$ and cardiovascular diseases (CVD). ${ }^{196}$ In the latter field, efforts have been spent to relate the levels of subpopulations of EVs positive to specific proteins or miRNAs with the most diffused CVDs, e.g. heart failure (e.g. CD144 ${ }^{+}$or mir- $192^{+} \mathrm{EVs}$ ) ${ }^{197,}, 198$ coronary artery disease (e.g. $\mathrm{CD}^{+} / \mathrm{CD} 45^{+}$or $\left.\alpha-\mathrm{SMA}^{+} \mathrm{EVs}\right)^{199}$, and stroke (e.g. mir- $9^{+}$or mir- $124^{+}$positive $\mathrm{EVs})^{200}$.

The second source of EV information, namely their colloidal properties, has been far less investigated than the compositional counterpart, although it proved to be significant. For instance, discrepancies in particle concentration between pathological versus healthy samples have been registered in multiple myeloma, ${ }^{201}$ bladder, ${ }^{202}$ pancreatic, ${ }^{203}$ and breast cancer studies. $^{204}$ Particle size is another biophysical factor influencing EV biological functions and uptake kinetics; differences in such parameter are reported in ovarian, ${ }^{205}$ and prostate cancer, ${ }^{206}$ but also in pre-eclampsia studies. ${ }^{207} \mathrm{EV}$ nanomechanical properties (e.g. membrane stiffness) could have similar importance for EV-cell interactions, but they have been less investigated than other potential physical biomarkers. So far, only one study examined EV nanomechanics in relation to pathology. ${ }^{208}$ In this seminal work, the authors compared the biophysical properties of two bladder cancer cell lines and one non-malignant, immortalized cell line. All the three types of EVs exhibited similar size and concentration but marked differences in membrane stiffness as observed through Quantitative Nano-Mapping Atomic Force Microscopy (QNM-AFM). Such difference was also associated with the ability of malignant EVs to induce local complement activation and augment endothelium permeability and leakiness, facilitating EV trans-endothelial transport.

\subsubsection{Lipoproteins}

Lipoproteins are key players in lipid metabolism. Their analysis is traditionally used to predict the onset of and to monitor metabolic dysfunctions, including obesity, diabetes mellitus and its complications, and cardiovascular diseases. Indeed, many disorders influence the concentration and the composition of lipoproteins, while the oxidation state of cargo lipids is heavily modified 
by oxidative stress occurring during inflammation, making lipoproteins invaluable biomarkers. (see specialized reviews for details. ${ }^{209-212}$ )

However, integrated data from nuclear magnetic resonance lipoprotein profile, metabolomics and soluble marker levels were found to be predictive of immunological recovery of HIV patients after anti-retroviral therapy, ${ }^{213}$ while lipoprotein infrared (IR) spectroscopy has been used for the detection of alcohol abuse. ${ }^{214}$ Indeed, chronic alcohol consumption causes liver to synthesize Fatty Acid Ethyl Esters (FAEE) from lipids and ethanol. FAEE are primarily bound to albumin and lipoproteins and can be easily detected using IR spectroscopy due to the presence of specific ester C-O-C bonds, which are normally absent in lipids. Moreover, differences in IR spectrograms of alcoholic people specifically correlates with two other parameters used as alcohol biomarker: AST/ALT enzymes and Carbohydrate-Deficient Transferrin (CDT) levels. Therefore, authors claim IR could represent a potential, non-destructive and costless tool for the detection of alcohol biomarkers, although several obstacles need to be overcome (e.g. short life of non-HDL compared to CDT or enzymes, dysregulation in lipoprotein levels due to drugs or disease etc.). Lipoproteins also contribute to the biomarker set with the nucleic acids they transport. HDLs carries significant amounts of miRNAs ${ }^{215}$, which are envisioned as potential markers for myocardial infarction, stable and unstable angina pectoris, ${ }^{216}$ hypercholesterolemia and atherosclerosis. ${ }^{217}$ This is supported by several in vitro studies highlighting the role of HDLmiRNAs in inflammation and atherosclerosis regulation. ${ }^{218,219}$ miRNA transport by lipoproteins other than HDLs is little investigated, but clues into LDL involvement exist. ${ }^{217}$

\subsubsection{Milk proteins, Casein Micelles and Fat Globules}

To date, fat globules or other milk secNPs have not been reported as sources for potential biomarkers. However, as previously discussed, both human and animal milk represent an excellent supply of other biomarkers, such as EVs and miRNAs 
Table 2. Selection of key review articles on clinical opportunities of secNPs. Note: not all of the articles have been presented in the main text, the table is intended as a further resource for the reader.

\begin{tabular}{|c|c|c|c|c|}
\hline & $\begin{array}{c}\text { Nanosized } \\
\text { macromolecular } \\
\text { complexes }\end{array}$ & $\begin{array}{c}\text { Extracellular } \\
\text { vesicles }\end{array}$ & Lipoproteins & $\begin{array}{c}\text { Milk proteins, } \\
\text { Casein } \\
\text { Micelles and } \\
\text { Fat Globules }\end{array}$ \\
\hline Drug delivery & $17,97-99$ & $103-106$ & $82,141,142$ & 146 \\
\hline Vaccines & $149-152$ & $43,153-156$ & $157-158$ & $/ /$ \\
\hline $\begin{array}{c}\text { Regenerative } \\
\text { Therapeutics }\end{array}$ & 159 & 162 & 171,172 & $/ /$ \\
\hline $\begin{array}{l}\text { Multiplexed } \\
\text { biomarkers }\end{array}$ & $/ /$ & $7,185,186$ & $209-212$ & $/ /$ \\
\hline
\end{tabular}




\section{Towards nanoparticles 2.0 and biogenic nanotechnology}

Nature has been exploiting NPs much longer than we have in our laboratories. The secretome (intended in its wider meaning) carries a variety of secNPs. These nanoparticles, either native/bare or modified, promise to be those "nanoparticles 2.0 " able to bring much needed physicochemical heterogeneity and intrinsic precision to nanomedicine, while opening exciting new perspectives. Researchers around the world are beginning to tackle this truly cross-disciplinary field, but the way is still long and scattered with cultural and technical obstacles. Comparative analysis and study of secNPs are very infrequent, the majority of the studies are focused on a specific biological and/or medical aspect of a given secNP class or subclass. To consolidate and harness a unified perspective, which also includes compelling physics, chemistry and material science, will be transformative. This review has been intended to provide a tool in this endeavor, by gathering and elaborating secNPs and their traits into a unique and concise framework.

A major challenge to secNPs translation is posed by the need for sustainable (in ethical, economic, scale and environmental terms) methods for production of high-grade secNP formulations (see for example $5,220,221$. Noteworthy, these objectives are actively pursued by two ongoing European projects (http://www.evfoundry.eu and https://ves4us.eu/project). To be brought to the society, sustainable production must be also standardized. The wider scientific community dealing with bionanomaterials is starting to vigorously debate and work on the topic. Recently, as a result of important collective efforts, general guidelines for minimal information reporting in bio-nano experimental literature ${ }^{222}$ and specific guidelines to minimal requirements for EV studies ${ }^{40}$ have been proposed. Sustainable standardized protocols and technology will be foundational towards large-scale production of secNP formulations which comply good manufacturing practices guidelines (EU GMP guidelines available at:

https://ec.europa.eu/health/documents/eudralex/vol-4 en) and eventually clinical-grade regulations. Standardization and regulatory initiatives will also open to large-scale clinical studies aimed at the validation of secNP formulations.

To the opposite side, scientists are trying to learn about single cell nature, as both physiological and pathological processes rely on the fine interplay between different kind of cells (https://www.nature. com/news/single-cell-biology-1.22241). Current single-cell experiments are focused on genomics, whereas soluble and nanostructured secretome remains overlooked. Adding secNPs to single-cell analyzed components could substantially improve the current picture 
of both physiological and pathological processes. This seems a feasible objective, as recently demonstrated by Li et al., who by integrating an optofluidic biosensor and a single cell bioreactor could successfully detect in real-time the spatial fingerprints of the angiogenetic growth factors secreted by a single cancer cell. ${ }^{223}$

From a wider alternative perspective, secNPs can be used as naturally pre-assembled building blocks for future "biogenic" surface- and nanotechnology, such as the realization of heterogeneous systems or the synthesis of living cells from scratch. ${ }^{224}$ For example, the first shall see the combination of synthetic surfaces or nanosystems with secNPs in order to upgrade artificial nanotechnology with the natural features of secNPs ${ }^{225-228}$, the latter the enrichment with secNPs of the current toolbox used for bottom-up assembly of synthetic protocells. ${ }^{229}$ 
State-of-the-art

The cell and its microenvironment rely on complex communication processes that are mediated by secreted nanoparticles (secNPs) which populate the 'Nanostructured secretome'.

\begin{tabular}{|l|l|l|l|}
\hline \multicolumn{2}{|c|}{ secNPs } & New clinical opportunities & \multicolumn{1}{c|}{ Other (nano)applications } \\
\hline Nanosized macromolecular complexes & $\begin{array}{l}\text { Drug delivery, vaccines, } \\
\text { regenerative therapeutics }\end{array}$ & \\
\hline \multirow{2}{*}{$\begin{array}{l}\text { Extracellular } \\
\text { vesicles (EVs) }\end{array}$} & Eukaryotic EVs & $\begin{array}{l}\text { Drug delivery, regenerative } \\
\text { therapeutics, multiplexed } \\
\text { biomarkers }\end{array}$ & $\begin{array}{l}\text { Supported lipid bilayers, biosensors, synthetic } \\
\text { micro- and nanosystems functionalization }\end{array}$ \\
\cline { 2 - 4 } Lipoproteins & Prokaryotic EVs & $\begin{array}{l}\text { Vaccines, multiplexed } \\
\text { biomarkers }\end{array}$ & \\
\hline $\begin{array}{l}\text { Milk proteins, casein micelles, fat } \\
\text { globules }\end{array}$ & $\begin{array}{l}\text { Drug delivery, regenerative } \\
\text { therapeutics, vaccines, } \\
\text { multiplexed biomarkers }\end{array}$ & \\
\hline & Drug delivery & \\
\hline
\end{tabular}

\section{Outstanding questions and perspectives}

- To date we are submerged by fundamental questions about secNP stability, biogenesis, targeting mechanisms etc. Nevertheless, we are already trying to find some direct applications for secNPs in bio-nanomedicine. Have we bitten more than we could chew?

- What are the unique physicochemical traits of each secNP class and sub-class? In turn, can they be robustly differentiated (separation and characterization)? Do secNP biophysical characteristics significantly determine their function?

- How is the secretion of secNPs regulated in the cell? Is there any signaling event that can boost the secretion of one secNP respect to another one? Could the secretion ratio of secNPs be related to any pathology?

- The immunogenicity of secNPs is debated. Could heterologous secNPs administered for therapeutic use cause severe immune response? Daily patients are receiving liquid or solid tissues from donors which act as cargo of biogenic nanoparticles without reporting severe immune reaction. Therefore, is immunogenicity something to worry about?

- SecNPs feature a big advantage: they do not have a replicatory machinery neither infectious nature, therefore they are safer than viruses. Are secNPs the perfect candidates for vaccines and gene therapy?

- How secNPs differ in terms of pharmacokinetics and pharmacodynamics? May these two paramount characteristics that influence dosing, benefit and adverse effects be improved/tailored by tweaking/engineering?

- May the synthetic nanotechnology come to the aid of biogenic nanotechnology by offering strategies to synthesize biocompatible NPs mimicking secNPs with the grade needed to meet quality and regulatory needs? Conversely, may tweaking/engineering of secNPs provide the needed control on their heterogeneity, which is (apparently) missed in crude samples?

- Can massive modification/production of secNP formulations with well-defined physical and chemical properties be achieved?

- Most of secNPs are conserved among different mammals. Can we open a new way toward interspecies studies? 


\section{Acknowledgements}

This work was supported by Università degli Studi di Brescia and Center for Colloid and Surface Science (CSGI) through the evFOUNDRY project, Horizon 2020- Future and emerging technologies (H2020-FETOPEN), ID: 801367; and by Associazione Italiana per la Ricerca sul Cancro (AIRC) through IG grant ID: 18493.

\section{Conflicts of interest}

The authors declare that there are no conflicts of interest.

\section{Author Contributions}

Conceptualization, P.B. and S.B.; writing — original draft preparation, all the authors; writingreview and editing, all the authors; visualization, A.Z.; supervision, P.B.; funding acquisition, P.B. and M.P.; please turn to the CRediT taxonomy for the term explanation. 


\section{References}

1. Y. Zhang and B. P. Orner, Int J Mol Sci, 2011, 12, 5406-5421.

2. K. Li, R. S. Rodosthenous, F. Kashanchi, T. Gingeras, S. J. Gould, L. S. Kuo, P. Kurre, H. Lee, J. N. Leonard, H. Liu, T. B. Lombo, S. Momma, J. P. Nolan, M. J. Ochocinska, D. M. Pegtel, Y. Sadovsky, F. Sanchez-Madrid, K. M. Valdes, K. C. Vickers, A. M. Weaver, K. W. Witwer, Y. Zeng, S. Das, R. L. Raffai and T. K. Howcroft, JCI Insight, $2018,3$.

3. A. V. Vlassov, S. Magdaleno, R. Setterquist and R. Conrad, Biochim Biophys Acta, 2012, 1820, 940-948.

4. H. Singh and S. Gallier, Food Hydrocolloids, 2017, 68, 81-89.

5. S. Raut, J. L. Dasseux, N. A. Sabnis, L. Mooberry and A. Lacko, Ther Deliv, 2018, 9, 257-268.

6. F. Rehan, N. Ahemad and M. Gupta, Colloids Surf B Biointerfaces, 2019, 179, 280-292.

7. L. Paolini, A. Zendrini and A. Radeghieri, Biomarkers in medicine, 2018, 12, 383-391.

8. $\quad$ S. L. N. Maas, X. O. Breakefield and A. M. Weaver, Trends Cell Biol, 2017, 27, 172188.

9. R. Vescovi, M. Monti, D. Moratto, L. Paolini, F. Consoli, L. Benerini, L. Melocchi, S. Calza, M. Chiudinelli, G. Rossi, M. Bugatti, M. Maio, E. Fonsatti, C. Farisoglio, M.

Simbolo, C. Almici, R. Verardi, A. Scarpa, P. Bergese, A. Manganoni, F. Facchetti and W. Vermi, Cancer Immunol Res, 2019, 7, 12-28.

10. E. Nolte-'t Hoen, T. Cremer, R. C. Gallo and L. B. Margolis, Proceedings of the National Academy of Sciences, 2016, 113, 9155.

11. F. Fernandez-Trillo, L. M. Grover, A. Stephenson-Brown, P. Harrison and P. M. Mendes, Angewandte Chemie (International ed. in English), 2017, 56, 3142-3160.

12. O. L. Arun Richard Chandrasekaran, Chemistry of Materials, 2016, 28, 5569-5581.

13. K. W. Lexa, E. Dolghih and M. P. Jacobson, PLoS One, 2014, 9, e93323.

14. X. M. He and D. C. Carter, Nature, 1992, 358, 209-215.

15. S. Sugio, A. Kashima, S. Mochizuki, M. Noda and K. Kobayashi, Protein Eng, 1999, 12, 439-446.

16. G. J. Quinlan, G. S. Martin and T. W. Evans, Hepatology, 2005, 41, 1211-1219.

17. B. Chiou and J. R. Connor, Pharmaceuticals (Basel), 2018, 11.

18. O. D. Mrowczynski, A. B. Madhankumar, B. Slagle-Webb, S. Y. Lee, B. E. Zacharia and J. R. Connor, Biochim Biophys Acta Gen Subj, 2017, 1861, 1921-1928.

19. M. Truman-Rosentsvit, D. Berenbaum, L. Spektor, L. A. Cohen, S. Belizowsky-Moshe, L. Lifshitz, J. Ma, W. Li, E. Kesselman, I. Abutbul-Ionita, D. Danino, L. Gutierrez, H. Li, K. Li, H. Lou, M. Regoni, M. Poli, F. Glaser, T. A. Rouault and E. G. Meyron-Holtz, Blood, 2018, 131, 342-352.

20. H. M. Baker, B. F. Anderson and E. N. Baker, Proc Natl Acad Sci U S A, 2003, 100, 3579-3583.

21. J. D. Arroyo, J. R. Chevillet, E. M. Kroh, I. K. Ruf, C. C. Pritchard, D. F. Gibson, P. S. Mitchell, C. F. Bennett, E. L. Pogosova-Agadjanyan, D. L. Stirewalt, J. F. Tait and M. Tewari, Proc Natl Acad Sci U S A, 2011, 108, 5003-5008.

22. Z. Ye, H. Jin and Q. Qian, J Cancer, 2015, 6, 877-882.

23. N. Yang, H. Zhang, M. Wang, Q. Hao and H. Sun, Sci Rep, 2012, 2, 999. 
24. P. D. Hempstead, S. J. Yewdall, A. R. Fernie, D. M. Lawson, P. J. Artymiuk, D. W. Rice, G. C. Ford and P. M. Harrison, Journal of molecular biology, 1997, 268, 424-448.

25. N. T. Schirle, G. A. Kinberger, H. F. Murray, W. F. Lima, T. P. Prakash and I. J. MacRae, Journal of the American Chemical Society, 2016, 138, 8694-8697.

26. B. Jachimska and A. Pajor, Bioelectrochemistry, 2012, 87, 138-146.

27. M. Kabiri, Z. Amiri-Tehranizadeh, A. Baratian, M. R. Saberi and J. Chamani, Molecules, 2012, 17, 3114-3147.

28. I. Moglia, M. Santiago, Á. Olivera-Nappa and M. Soler, Journal of Inorganic Biochemistry, 2018, 183, 184-190.

29. H. P. Erickson, Biol Proced Online, 2009, 11, 32-51.

30. M. A. Kiselev, A. Gryzunov Iu, G. E. Dobretsov and M. N. Komarova, Biofizika, 2001, 46, 423-427.

31. F. Kilar and I. Simon, Biophysical journal, 1985, 48, 799-802.

32. M. L. Quillin and B. W. Matthews, Acta Crystallographica Section D, 2000, 56, 791-794.

33. H. Fischer, I. Polikarpov and A. F. Craievich, Protein science : a publication of the Protein Society, 2004, 13, 2825-2828.

34. G. van Niel, G. D'Angelo and G. Raposo, Nature Reviews Molecular Cell Biology, 2018, 19, 213.

35. M. Mathieu, L. Martin-Jaular, G. Lavieu and C. Thery, Nat Cell Biol, 2019, 21, 9-17.

36. B. L. Deatherage and B. T. Cookson, Infection and Immunity, 2012, 80, 1948.

37. M. Yanez-Mo, P. R. Siljander, Z. Andreu, A. B. Zavec, F. E. Borras, E. I. Buzas, K. Buzas, E. Casal, F. Cappello, J. Carvalho, E. Colas, A. Cordeiro-da Silva, S. Fais, J. M. Falcon-Perez, I. M. Ghobrial, B. Giebel, M. Gimona, M. Graner, I. Gursel, M. Gursel, N. H. Heegaard, A. Hendrix, P. Kierulf, K. Kokubun, M. Kosanovic, V. Kralj-Iglic, E. M. Kramer-Albers, S. Laitinen, C. Lasser, T. Lener, E. Ligeti, A. Line, G. Lipps, A. Llorente, J. Lotvall, M. Mancek-Keber, A. Marcilla, M. Mittelbrunn, I. Nazarenko, E. N. Nolte-'t Hoen, T. A. Nyman, L. O'Driscoll, M. Olivan, C. Oliveira, E. Pallinger, H. A. Del Portillo, J. Reventos, M. Rigau, E. Rohde, M. Sammar, F. Sanchez-Madrid, N. Santarem, K. Schallmoser, M. S. Ostenfeld, W. Stoorvogel, R. Stukelj, S. G. Van der Grein, M. H. Vasconcelos, M. H. Wauben and O. De Wever, J Extracell Vesicles, 2015, 4, 27066.

38. G. Raposo and W. Stoorvogel, J Cell Biol, 2013, 200, 373-383.

39. E. Cocucci, G. Racchetti and J. Meldolesi, Trends Cell Biol, 2009, 19, 43-51.

40. C. Thery, K. W. Witwer, E. Aikawa, M. J. Alcaraz, J. D. Anderson, R. Andriantsitohaina, A. Antoniou, T. Arab, F. Archer, G. K. Atkin-Smith, D. C. Ayre, J. M. Bach, D. Bachurski, H. Baharvand, L. Balaj, S. Baldacchino, N. N. Bauer, A. A. Baxter, M. Bebawy, C. Beckham, A. Bedina Zavec, A. Benmoussa, A. C. Berardi, P. Bergese, E. Bielska, C. Blenkiron, S. Bobis-Wozowicz, E. Boilard, W. Boireau, A. Bongiovanni, F. E. Borras, S. Bosch, C. M. Boulanger, X. Breakefield, A. M. Breglio, M. A. Brennan, D. R. Brigstock, A. Brisson, M. L. Broekman, J. F. Bromberg, P. Bryl-Gorecka, S. Buch, A. H. Buck, D. Burger, S. Busatto, D. Buschmann, B. Bussolati, E. I. Buzas, J. B. Byrd, G. Camussi, D. R. Carter, S. Caruso, L. W. Chamley, Y. T. Chang, C. Chen, S. Chen, L. Cheng, A. R. Chin, A. Clayton, S. P. Clerici, A. Cocks, E. Cocucci, R. J. Coffey, A. Cordeiro-da-Silva, Y. Couch, F. A. Coumans, B. Coyle, R. Crescitelli, M. F. Criado, C. D'Souza-Schorey, S. Das, A. Datta Chaudhuri, P. de Candia, E. F. De Santana, O. De Wever, H. A. Del Portillo, T. Demaret, S. Deville, A. Devitt, B. Dhondt, D. Di Vizio, L. 
C. Dieterich, V. Dolo, A. P. Dominguez Rubio, M. Dominici, M. R. Dourado, T. A. Driedonks, F. V. Duarte, H. M. Duncan, R. M. Eichenberger, K. Ekstrom, S. El Andaloussi, C. Elie-Caille, U. Erdbrugger, J. M. Falcon-Perez, F. Fatima, J. E. Fish, M. Flores-Bellver, A. Forsonits, A. Frelet-Barrand, F. Fricke, G. Fuhrmann, S. Gabrielsson, A. Gamez-Valero, C. Gardiner, K. Gartner, R. Gaudin, Y. S. Gho, B. Giebel, C. Gilbert, M. Gimona, I. Giusti, D. C. Goberdhan, A. Gorgens, S. M. Gorski, D. W. Greening, J. C. Gross, A. Gualerzi, G. N. Gupta, D. Gustafson, A. Handberg, R. A. Haraszti, P. Harrison, H. Hegyesi, A. Hendrix, A. F. Hill, F. H. Hochberg, K. F. Hoffmann, B. Holder, H. Holthofer, B. Hosseinkhani, G. Hu, Y. Huang, V. Huber, S. Hunt, A. G. Ibrahim, T. Ikezu, J. M. Inal, M. Isin, A. Ivanova, H. K. Jackson, S. Jacobsen, S. M. Jay, M. Jayachandran, G. Jenster, L. Jiang, S. M. Johnson, J. C. Jones, A. Jong, T. JovanovicTalisman, S. Jung, R. Kalluri, S. I. Kano, S. Kaur, Y. Kawamura, E. T. Keller, D. Khamari, E. Khomyakova, A. Khvorova, P. Kierulf, K. P. Kim, T. Kislinger, M. Klingeborn, D. J. Klinke, 2nd, M. Kornek, M. M. Kosanovic, A. F. Kovacs, E. M. Kramer-Albers, S. Krasemann, M. Krause, I. V. Kurochkin, G. D. Kusuma, S. Kuypers, S. Laitinen, S. M. Langevin, L. R. Languino, J. Lannigan, C. Lasser, L. C. Laurent, G. Lavieu, E. Lazaro-Ibanez, S. Le Lay, M. S. Lee, Y. X. F. Lee, D. S. Lemos, M. Lenassi, A. Leszczynska, I. T. Li, K. Liao, S. F. Libregts, E. Ligeti, R. Lim, S. K. Lim, A. Line, K. Linnemannstons, A. Llorente, C. A. Lombard, M. J. Lorenowicz, A. M. Lorincz, J. Lotvall, J. Lovett, M. C. Lowry, X. Loyer, Q. Lu, B. Lukomska, T. R. Lunavat, S. L. Maas, H. Malhi, A. Marcilla, J. Mariani, J. Mariscal, E. S. Martens-Uzunova, L. MartinJaular, M. C. Martinez, V. R. Martins, M. Mathieu, S. Mathivanan, M. Maugeri, L. K. McGinnis, M. J. McVey, D. G. Meckes, Jr., K. L. Meehan, I. Mertens, V. R. Minciacchi, A. Moller, M. Moller Jorgensen, A. Morales-Kastresana, J. Morhayim, F. Mullier, M. Muraca, L. Musante, V. Mussack, D. C. Muth, K. H. Myburgh, T. Najrana, M. Nawaz, I. Nazarenko, P. Nejsum, C. Neri, T. Neri, R. Nieuwland, L. Nimrichter, J. P. Nolan, E. N. Nolte-'t Hoen, N. Noren Hooten, L. O'Driscoll, T. O'Grady, A. O'Loghlen, T. Ochiya, M. Olivier, A. Ortiz, L. A. Ortiz, X. Osteikoetxea, O. Ostergaard, M. Ostrowski, J. Park, D. M. Pegtel, H. Peinado, F. Perut, M. W. Pfaffl, D. G. Phinney, B. C. Pieters, R. C. Pink, D. S. Pisetsky, E. Pogge von Strandmann, I. Polakovicova, I. K. Poon, B. H. Powell, I. Prada, L. Pulliam, P. Quesenberry, A. Radeghieri, R. L. Raffai, S. Raimondo, J. Rak, M. I. Ramirez, G. Raposo, M. S. Rayyan, N. Regev-Rudzki, F. L. Ricklefs, P. D. Robbins, D. D. Roberts, S. C. Rodrigues, E. Rohde, S. Rome, K. M. Rouschop, A. Rughetti, A. E. Russell, P. Saa, S. Sahoo, E. Salas-Huenuleo, C. Sanchez, J. A. Saugstad, M. J. Saul, R. M. Schiffelers, R. Schneider, T. H. Schoyen, A. Scott, E. Shahaj, S. Sharma, O.

Shatnyeva, F. Shekari, G. V. Shelke, A. K. Shetty, K. Shiba, P. R. Siljander, A. M. Silva, A. Skowronek, O. L. Snyder, 2nd, R. P. Soares, B. W. Sodar, C. Soekmadji, J. Sotillo, P. D. Stahl, W. Stoorvogel, S. L. Stott, E. F. Strasser, S. Swift, H. Tahara, M. Tewari, K. Timms, S. Tiwari, R. Tixeira, M. Tkach, W. S. Toh, R. Tomasini, A. C. Torrecilhas, J. P. Tosar, V. Toxavidis, L. Urbanelli, P. Vader, B. W. van Balkom, S. G. van der Grein, J. Van Deun, M. J. van Herwijnen, K. Van Keuren-Jensen, G. van Niel, M. E. van Royen, A. J. van Wijnen, M. H. Vasconcelos, I. J. Vechetti, Jr., T. D. Veit, L. J. Vella, E. Velot, F. J. Verweij, B. Vestad, J. L. Vinas, T. Visnovitz, K. V. Vukman, J. Wahlgren, D. C. Watson, M. H. Wauben, A. Weaver, J. P. Webber, V. Weber, A. M. Wehman, D. J. Weiss, J. A. Welsh, S. Wendt, A. M. Wheelock, Z. Wiener, L. Witte, J. Wolfram, A. Xagorari, P. Xander, J. Xu, X. Yan, M. Yanez-Mo, H. Yin, Y. Yuana, V. Zappulli, J. 
Zarubova, V. Zekas, J. Y. Zhang, Z. Zhao, L. Zheng, A. R. Zheutlin, A. M. Zickler, P. Zimmermann, A. M. Zivkovic, D. Zocco and E. K. Zuba-Surma, Journal of extracellular vesicles, 2018, 7, 1535750.

41. R. Xu, A. Rai, M. Chen, W. Suwakulsiri, D. W. Greening and R. J. Simpson, Nature reviews. Clinical oncology, 2018, 15, 617-638.

42. Y. Seo, H. S. Kim and I. S. Hong, Stem Cells Int, 2019, 2019, 5126156.

43. K. Watanabe, Applied microbiology and biotechnology, 2016, 100, 9837-9843.

44. N. Karimi, A. Cvjetkovic, S. C. Jang, R. Crescitelli, M. A. Hosseinpour Feizi, R. Nieuwland, J. Lötvall and C. Lässer, Cellular and Molecular Life Sciences, 2018, 75, 2873-2886.

45. T. Soares Martins, J. Catita, I. Martins Rosa, A. B. d. C. E. S. O and A. G. Henriques, PLoS One, 2018, 13, e0198820.

46. C. Lässer, S. C. Jang and J. Lötvall, Molecular Aspects of Medicine, 2018, 60, 1-14.

47. T. Skotland, K. Sandvig and A. Llorente, Progress in Lipid Research, 2017, 66, 30-41.

48. I. Ramasamy, Clin Chem Lab Med, 2014, 52, 1695-1727.

49. K. R. Feingold and C. Grunfeld, in Endotext, eds. K. R. Feingold, B. Anawalt, A. Boyce, G. Chrousos, K. Dungan, A. Grossman, J. M. Hershman, G. Kaltsas, C. Koch, P. Kopp, M. Korbonits, R. McLachlan, J. E. Morley, M. New, L. Perreault, J. Purnell, R. Rebar, F. Singer, D. L. Trence, A. Vinik and D. P. Wilson, South Dartmouth (MA), 2000.

50. H. Ishikawa, H. Yamada, N. Taromaru, K. Kondo, A. Nagura, M. Yamazaki, Y. Ando, E. Munetsuna, K. Suzuki, K. Ohashi and R. Teradaira, Ann Clin Biochem, 2017, 54, 134142.

51. N. Auge, F. Maupas-Schwalm, M. Elbaz, J. C. Thiers, A. Waysbort, S. Itohara, H. W. Krell, R. Salvayre and A. Negre-Salvayre, Circulation, 2004, 110, 571-578.

52. T. Murtola, T. A. Vuorela, M. T. Hyvönen, S.-J. Marrink, M. Karttunen and I. Vattulainen, Soft Matter, 2011, 7, 8135-8141.

53. M. Rodriguez, M. Guardiola, I. Oliva, J. Carles Vallve, R. Ferre, L. Masana, S. Parra, J. Ribalta and A. Castro, International journal of rheumatic diseases, 2019, 22, 480-487.

54. M. A. Elsheikh, Y. S. R. Elnaggar, D. Y. Otify and O. Y. Abdallah, Pharmaceutical Research, 2018, 35, 18.

55. K. K. Ng, J. F. Lovell and G. Zheng, Accounts of Chemical Research, 2011, 44, 11051113.

56. H. Zhang, D. Freitas, H. S. Kim, K. Fabijanic, Z. Li, H. Chen, M. T. Mark, H. Molina, A. B. Martin, L. Bojmar, J. Fang, S. Rampersaud, A. Hoshino, I. Matei, C. M. Kenific, M. Nakajima, A. P. Mutvei, P. Sansone, W. Buehring, H. Wang, J. P. Jimenez, L. CohenGould, N. Paknejad, M. Brendel, K. Manova-Todorova, A. Magalhães, J. A. Ferreira, H. Osório, A. M. Silva, A. Massey, J. R. Cubillos-Ruiz, G. Galletti, P. Giannakakou, A. M. Cuervo, J. Blenis, R. Schwartz, M. S. Brady, H. Peinado, J. Bromberg, H. Matsui, C. A. Reis and D. Lyden, Nature Cell Biology, 2018, 20, 332-343.

57. Q. Zhang, J. N. Higginbotham, D. K. Jeppesen, Y.-P. Yang, W. Li, E. T. McKinley, R. Graves-Deal, J. Ping, C. M. Britain, K. A. Dorsett, C. L. Hartman, D. A. Ford, R. M. Allen, K. C. Vickers, Q. Liu, J. L. Franklin, S. L. Bellis and R. J. Coffey, Cell Reports, 2019, 27, 940-954.e946.

58. $\quad$ N. J. Andreas, B. Kampmann and K. Mehring Le-Doare, Early Hum Dev, 2015, 91, 629635.

59. N. Argov, D. G. Lemay and J. B. German, Trends Food Sci Technol, 2008, 19. 
60. C. Lopez, C. Cauty and F. Guyomarc'h, European Journal of Lipid Science and Technology, 2019, 121, 1800201.

61. W. Holzmüller and U. Kulozik, International Dairy Journal, 2016, 61, 51-66.

62. O. Ménard, S. Ahmad, F. Rousseau, V. Briard-Bion, F. Gaucheron and C. Lopez, Food Chemistry, 2010, 120, 544-551.

63. M.-C. Michalski, F. Michel, D. Sainmont and V. Briard, Colloids and Surfaces B: Biointerfaces, 2002, 23, 23-30.

64. M. C. Michalski, V. Briard, F. Michel, F. Tasson and P. Poulain, Journal of Dairy Science, 2005, 88, 1927-1940.

65. B. Ingham, G. D. Erlangga, A. Smialowska, N. M. Kirby, C. Wang, L. Matia-Merino, R. G. Haverkamp and A. J. Carr, Soft matter, 2015, 11, 2723-2725.

66. C. G. de Kruif, T. Huppertz, V. S. Urban and A. V. Petukhov, Advances in colloid and interface science, 2012, 171-172, 36-52.

67. A. Jukkola and O. J. Rojas, Advances in Colloid and Interface Science, 2017, 245, 92101.

68. Q. Chen, S. Rozovsky and W. Chen, Chem Commun (Camb), 2017, 53, 7569-7572.

69. F. A. W. Coumans, A. R. Brisson, E. I. Buzas, F. Dignat-George, E. E. E. Drees, S. ElAndaloussi, C. Emanueli, A. Gasecka, A. Hendrix, A. F. Hill, R. Lacroix, Y. Lee, T. G. van Leeuwen, N. Mackman, I. Mager, J. P. Nolan, E. van der Pol, D. M. Pegtel, S. Sahoo, P. R. M. Siljander, G. Sturk, O. de Wever and R. Nieuwland, Circ Res, 2017, 120, 16321648.

70. S. Busatto, G. Vilanilam, T. Ticer, W. L. Lin, D. W. Dickson, S. Shapiro, P. Bergese and J. Wolfram, Cells, 2018, 7.

71. K. W. Witwer, E. I. Buzas, L. T. Bemis, A. Bora, C. Lasser, J. Lotvall, E. N. Nolte-'t Hoen, M. G. Piper, S. Sivaraman, J. Skog, C. Thery, M. H. Wauben and F. Hochberg, J Extracell Vesicles, 2013, 2.

72. C. Y. Yang, J. L. Raya, H. H. Chen, C. H. Chen, Y. Abe, H. J. Pownall, A. A. Taylor and C. V. Smith, Arterioscler Thromb Vasc Biol, 2003, 23, 1083-1090.

73. C. Gardiner, D. Di Vizio, S. Sahoo, C. Thery, K. W. Witwer, M. Wauben and A. F. Hill, J Extracell Vesicles, 2016, 5, 32945.

74. M. A. Livshits, E. Khomyakova, E. G. Evtushenko, V. N. Lazarev, N. A. Kulemin, S. E. Semina, E. V. Generozov and V. M. Govorun, Sci Rep, 2015, 5, 17319.

75. J. Z. Nordin, Y. Lee, P. Vader, I. Mager, H. J. Johansson, W. Heusermann, O. P. Wiklander, M. Hallbrink, Y. Seow, J. J. Bultema, J. Gilthorpe, T. Davies, P. J. Fairchild, S. Gabrielsson, N. C. Meisner-Kober, J. Lehtio, C. I. Smith, M. J. Wood and S. El Andaloussi, Nanomedicine, 2015, 11, 879-883.

76. W. Wang, X. J. Huang, J. D. Cao, P. Lan and W. Wu, Acta Biomater, 2014, 10, 234-243.

77. T. A. Hartjes, S. Mytnyk, G. W. Jenster, V. van Steijn and M. E. van Royen, Bioengineering (Basel), 2019, 6.

78. I. Furi, F. Momen-Heravi and G. Szabo, Ann Transl Med, 2017, 5, 263.

79. A. Salvi, M. Vezzoli, S. Busatto, L. Paolini, T. Faranda, E. Abeni, M. Caracausi, F. Antonaros, A. Piovesan, C. Locatelli, G. Cocchi, G. Alvisi, G. De Petro, D. Ricotta, P. Bergese and A. Radeghieri, Int J Mol Med, 2019, 43, 2303-2318.

80. M. Y. Konoshenko, E. A. Lekchnov, A. V. Vlassov and P. P. Laktionov, Biomed Res Int, 2018, 2018, 8545347. 
81. L. Paolini, A. Zendrini, G. Di Noto, S. Busatto, E. Lottini, A. Radeghieri, A. Dossi, A. Caneschi, D. Ricotta and P. Bergese, Sci Rep, 2016, 6, 23550.

82. J. Karttunen, M. Heiskanen, V. Navarro-Ferrandis, S. Das Gupta, A. Lipponen, N. Puhakka, K. Rilla, A. Koistinen and A. Pitkanen, J Extracell Vesicles, 2019, 8, 1555410.

83. S. Busatto, A. Giacomini, C. Montis, R. Ronca and P. Bergese, Anal Chem, 2018, 90, $7855-7861$.

84. A. Gamez-Valero, M. Monguio-Tortajada, L. Carreras-Planella, M. Franquesa, K. Beyer and F. E. Borras, Sci Rep, 2016, 6, 33641.

85. M. I. Ramirez, M. G. Amorim, C. Gadelha, I. Milic, J. A. Welsh, V. M. Freitas, M. Nawaz, N. Akbar, Y. Couch, L. Makin, F. Cooke, A. L. Vettore, P. X. Batista, R. Freezor, J. A. Pezuk, L. Rosa-Fernandes, A. C. O. Carreira, A. Devitt, L. Jacobs, I. T. Silva, G. Coakley, D. N. Nunes, D. Carter, G. Palmisano and E. Dias-Neto, Nanoscale, 2018, 10, 881-906.

86. J. C. Contreras-Naranjo, H. J. Wu and V. M. Ugaz, Lab Chip, 2017, 17, 3558-3577.

87. P. Cizmar and Y. Yuana, Methods Mol Biol, 2017, 1660, 221-232.

88. C. Gardiner, M. Shaw, P. Hole, J. Smith, D. Tannetta, C. W. Redman and I. L. Sargent, $J$ Extracell Vesicles, 2014, 3, 25361.

89. C. Montis, A. Zendrini, F. Valle, S. Busatto, L. Paolini, A. Radeghieri, A. Salvatore, D. Berti and P. Bergese, Colloids Surf B Biointerfaces, 2017, 158, 331-338.

90. S. L. Maas, J. De Vrij and M. L. Broekman, J Vis Exp, 2014, DOI: 10.3791/51623, e51623.

91. D. Maiolo, L. Paolini, G. Di Noto, A. Zendrini, D. Berti, P. Bergese and D. Ricotta, Anal Chem, 2015, 87, 4168-4176.

92. A. Gorgens, M. Bremer, R. Ferrer-Tur, F. Murke, T. Tertel, P. A. Horn, S. Thalmann, J. A. Welsh, C. Probst, C. Guerin, C. M. Boulanger, J. C. Jones, H. Hanenberg, U. Erdbrugger, J. Lannigan, F. L. Ricklefs, S. El-Andaloussi and B. Giebel, J Extracell Vesicles, 2019, 8, 1587567.

93. C. Campos-Silva, H. Suarez, R. Jara-Acevedo, E. Linares-Espinos, L. Martinez-Pineiro, M. Yanez-Mo and M. Vales-Gomez, Sci Rep, 2019, 9, 2042.

94. R. Bandu, J. W. Oh and K. P. Kim, Exp Mol Med, 2019, 51, 30.

95. H. Shao, H. Im, C. M. Castro, X. Breakefield, R. Weissleder and H. Lee, Chem Rev, 2018, 118, 1917-1950.

96. B. Hosseinkhani, N. van den Akker, J. D'Haen, M. Gagliardi, T. Struys, I. Lambrichts, J. Waltenberger, I. Nelissen, J. Hooyberghs, D. G. M. Molin and L. Michiels, Nanomedicine, 2017, 13, 1663-1671.

97. J. Mihaly, R. Deak, I. C. Szigyarto, A. Bota, T. Beke-Somfai and Z. Varga, Biochim Biophys Acta Biomembr, 2017, 1859, 459-466.

98. S. Saito, K. Hiemori, K. Kiyoi and H. Tateno, Sci Rep, 2018, 8, 3997.

99. M. Chalfie, Y. Tu, G. Euskirchen, W. W. Ward and D. C. Prasher, Science (New York, N.Y.), 1994, 263, 802-805.

100. S. Inouye and F. I. Tsuji, FEBS letters, 1994, 341, 277-280.

101. J. Royes, O. Ilioaia, Q. Lubart, F. Angius, G. V. Dubacheva, M. Bally, B. Miroux and C. Tribet, Angew Chem Int Ed Engl, 2019, 58, 7395-7399.

102. P. Garcia-Manrique, M. Matos, G. Gutierrez, C. Pazos and M. C. Blanco-Lopez, J Extracell Vesicles, 2018, 7, 1422676. 
103. O. G. de Jong, M. C. Verhaar, Y. Chen, P. Vader, H. Gremmels, G. Posthuma, R. M. Schiffelers, M. Gucek and B. W. van Balkom, J Extracell Vesicles, 2012, 1.

104. D. A. Bricarello, J. T. Smilowitz, A. M. Zivkovic, J. B. German and A. N. Parikh, ACS Nano, 2011, 5, 42-57.

105. J. Chandrapala, G. J. Martin, S. E. Kentish and M. Ashokkumar, Ultrason Sonochem, 2014, 21, 1658-1665.

106. J. P. Armstrong, M. N. Holme and M. M. Stevens, ACS Nano, 2017, 11, 69-83.

107. E. J. Lee, N. K. Lee and I. S. Kim, Adv Drug Deliv Rev, 2016, 106, 157-171.

108. C. S. Thaxton, J. S. Rink, P. C. Naha and D. P. Cormode, Adv Drug Deliv Rev, 2016, 106, 116-131.

109. K. E. Gilligan and R. M. Dwyer, Int J Mol Sci, 2017, 18.

110. J. O. Jeon, S. Kim, E. Choi, K. Shin, K. Cha, I. S. So, S. J. Kim, E. Jun, D. Kim, H. J. Ahn, B. H. Lee, S. H. Lee and I. S. Kim, ACS Nano, 2013, 7, 7462-7471.

111. M. Liang, C. Gao, Y. Wang, W. Gong, S. Fu, L. Cui, Z. Zhou, X. Chu, Y. Zhang, Q. Liu, X. Zhao, B. Zhao, M. Yang, Z. Li, C. Yang, X. Xie, Y. Yang and C. Gao, Drug Deliv, 2018, 25, 1652-1663.

112. T. Smyth, K. Petrova, N. M. Payton, I. Persaud, J. S. Redzic, M. W. Graner, P. SmithJones and T. J. Anchordoquy, Bioconjug Chem, 2014, 25, 1777-1784.

113. H. Lee, H. Park, G. J. Noh and E. S. Lee, Carbohydr Polym, 2018, 202, 323-333.

114. J. B. Simonsen, J Extracell Vesicles, 2019, 8, 1582237.

115. P. Gangadaran, C. M. Hong and B. C. Ahn, Biomed Res Int, 2017, 2017, 9158319.

116. C. P. Lai, B. A. Tannous and X. O. Breakefield, Methods Mol Biol, 2014, 1098, 249-258.

117. J. Cai, Y. Han, H. Ren, C. Chen, D. He, L. Zhou, G. M. Eisner, L. D. Asico, P. A. Jose and C. Zeng, Journal of molecular cell biology, 2013, 5, 227-238.

118. K. M. McMahon, R. K. Mutharasan, S. Tripathy, D. Veliceasa, M. Bobeica, D. K. Shumaker, A. J. Luthi, B. T. Helfand, H. Ardehali, C. A. Mirkin, O. Volpert and C. S. Thaxton, Nano letters, 2011, 11, 1208-1214.

119. N. J. Bitto, R. Chapman, S. Pidot, A. Costin, C. Lo, J. Choi, T. D'Cruze, E. C. Reynolds, S. G. Dashper, L. Turnbull, C. B. Whitchurch, T. P. Stinear, K. J. Stacey and R. L. Ferrero, Sci Rep, 2017, 7, 7072.

120. K. Isaac-Olive, B. E. Ocampo-Garcia, L. Aranda-Lara, C. L. Santos-Cuevas, N. P. Jimenez-Mancilla, M. A. Luna-Gutierrez, L. A. Medina, B. Nagarajan, N. Sabnis, S. Raut, L. Prokai and A. G. Lacko, Nanoscale, 2019, 11, 541-551.

121. Q. Dai, S. Wilhelm, D. Ding, A. M. Syed, S. Sindhwani, Y. Zhang, Y. Y. Chen, P. MacMillan and W. C. W. Chan, ACS Nano, 2018, 12, 8423-8435.

122. W. C. W. Chan, Accounts of Chemical Research, 2017, 50, 627-632.

123. M. T. Larsen, M. Kuhlmann, M. L. Hvam and K. A. Howard, Mol Cell Ther, 2016, 4, 3.

124. M. Khoshnejad, H. Parhiz, V. V. Shuvaev, I. J. Dmochowski and V. R. Muzykantov, J Control Release, 2018, 282, 13-24.

125. A. E. Pottash, C. Kuffner, M. Noonan-Shueh and S. M. Jay, J Biol Eng, 2019, 13, 19.

126. Y. Zhang, Z. Guo, Z. Cao, W. Zhou, Y. Zhang, Q. Chen, Y. Lu, X. Chen, Q. Guo, C. Li, D. Liang, T. Sun and C. Jiang, Biomaterials, 2018, 183, 243-257.

127. S. Dostalova, H. Polanska, M. Svobodova, J. Balvan, O. Krystofova, Y. Haddad, S. Krizkova, M. Masarik, T. Eckschlager, M. Stiborova, Z. Heger and V. Adam, Sci Rep, $2018,8,8867$. 
128. J. Li, C. Wu, W. Wang, Y. He, E. Elkayam, L. Joshua-Tor and P. T. Hammond, Proc Natl Acad Sci U S A, 2018, 115, E2696-E2705.

129. J. P. K. Armstrong and M. M. Stevens, Adv Drug Deliv Rev, 2018, 130, 12-16.

130. P. Vader, E. A. Mol, G. Pasterkamp and R. M. Schiffelers, Adv Drug Deliv Rev, 2016, 106, 148-156.

131. S. M. Kim and H. S. Kim, Stem Cell Investig, 2017, 4, 74.

132. M. Piffoux, A. Nicolas-Boluda, V. Mulens-Arias, S. Richard, G. Rahmi, F. Gazeau, C. Wilhelm and A. K. A. Silva, Adv Drug Deliv Rev, 2019, 138, 247-258.

133. D. S. Chulpanova, K. V. Kitaeva, V. James, A. A. Rizvanov and V. V. Solovyeva, Front Immunol, 2018, 9, 1534.

134. W. M. Usman, T. C. Pham, Y. Y. Kwok, L. T. Vu, V. Ma, B. Peng, Y. S. Chan, L. Wei, S. M. Chin, A. Azad, A. B. He, A. Y. H. Leung, M. Yang, N. Shyh-Chang, W. C. Cho, J. Shi and M. T. N. Le, Nat Commun, 2018, 9, 2359.

135. A. H. Alhasan, P. C. Patel, C. H. Choi and C. A. Mirkin, Small, 2014, 10, 186-192.

136. M. Garofalo, A. Villa, N. Rizzi, L. Kuryk, B. Rinner, V. Cerullo, M. Yliperttula, V. Mazzaferro and P. Ciana, J Control Release, 2019, 294, 165-175.

137. P. Lv, X. Liu, X. Chen, C. Liu, Y. Zhang, C. Chu, J. Wang, X. Wang, X. Chen and G. Liu, Nano Lett, 2019, 19, 2993-3001.

138. L. Alvarez-Erviti, Y. Seow, H. Yin, C. Betts, S. Lakhal and M. J. Wood, Nat Biotechnol, 2011, 29, 341-345.

139. E. Cho, G. H. Nam, Y. Hong, Y. K. Kim, D. H. Kim, Y. Yang and I. S. Kim, J Control Release, 2018, 279, 326-335.

140. M. J. Haney, N. L. Klyachko, Y. Zhao, R. Gupta, E. G. Plotnikova, Z. He, T. Patel, A. Piroyan, M. Sokolsky, A. V. Kabanov and E. V. Batrakova, J Control Release, 2015, 207, 18-30.

141. H. Huang, W. Cruz, J. Chen and G. Zheng, Wiley Interdiscip Rev Nanomed Nanobiotechnol, 2015, 7, 298-314.

142. A. G. Lacko, N. A. Sabnis, B. Nagarajan and W. J. McConathy, Frontiers in pharmacology, 2015, 6, 247.

143. Q. L. Zhu, Y. Zhou, M. Guan, X. F. Zhou, S. D. Yang, Y. Liu, W. L. Chen, C. G. Zhang, Z. Q. Yuan, C. Liu, A. J. Zhu and X. N. Zhang, Biomaterials, 2014, 35, 5965-5976.

144. Y. Ding, W. Wang, M. Feng, Y. Wang, J. Zhou, X. Ding, X. Zhou, C. Liu, R. Wang and Q. Zhang, Biomaterials, 2012, 33, 8893-8905.

145. L. Cui, Y. Wang, M. Liang, X. Chu, S. Fu, C. Gao, Q. Liu, W. Gong, M. Yang, Z. Li, L. Yu, C. Yang, Z. Su, X. Xie, Y. Yang and C. Gao, Drug delivery, 2018, 25, 1865-1876.

146. A. O. Elzoghby, W. S. El-Fotoh and N. A. Elgindy, J Control Release, 2011, 153, 206216.

147. M. L. C. Picchio, J. C.; Nagel, G.; Wedepohl, S.; Minari, R. J.; Alvarez Igarzabal, C. A.; Gugliotta, L. M.; and Calderón, M., Polymer Chemistry, 2018, 9, 3499-3510.

148. J. Lopez-Sagaseta, E. Malito, R. Rappuoli and M. J. Bottomley, Computational and structural biotechnology journal, 2016, 14, 58-68.

149. G. Zhu, G. M. Lynn, O. Jacobson, K. Chen, Y. Liu, H. Zhang, Y. Ma, F. Zhang, R. Tian, Q. Ni, S. Cheng, Z. Wang, N. Lu, B. C. Yung, Z. Wang, L. Lang, X. Fu, A. Jin, I. D. Weiss, H. Vishwasrao, G. Niu, H. Shroff, D. M. Klinman, R. A. Seder and X. Chen, Nature Communications, 2017, 8, 1954. 
150. M. Kanekiyo, C. J. Wei, H. M. Yassine, P. M. McTamney, J. C. Boyington, J. R. Whittle, S. S. Rao, W. P. Kong, L. Wang and G. J. Nabel, Nature, 2013, 499, 102-106.

151. Z. Wang, L. Xu, H. Yu, P. Lv, Z. Lei, Y. Zeng, G. Liu and T. Cheng, Biomaterials science, 2019, 7, 1794-1800.

152. W. Wang, Z. Liu, X. Zhou, Z. Guo, J. Zhang, P. Zhu, S. Yao and M. Zhu, Nanomedicine : nanotechnology, biology, and medicine, 2019, 16, 69-78.

153. K. Tan, R. Li, X. Huang and Q. Liu, Frontiers in Microbiology, 2018, 9.

154. R. Acevedo, S. Fernandez, C. Zayas, A. Acosta, M. Sarmiento, V. Ferro, E. Rosenqvist, C. Campa, D. Cardoso, L. Garcia and J. Perez, Frontiers in Immunology, 2014, 5.

155. G. G. Mekonnen, M. Pearson, A. Loukas and J. Sotillo, Expert Review of Vaccines, 2018, 17, 197-205.

156. S. Montaner-Tarbes, F. E. Borrás, M. Montoya, L. Fraile and H. A. del Portillo, Veterinary Research, 2016, 47, 59.

157. P. Kadiyala, D. Li, F. M. Nuñez, D. Altshuler, R. Doherty, R. Kuai, M. Yu, N. Kamran, M. Edwards, J. J. Moon, P. R. Lowenstein, M. G. Castro and A. Schwendeman, ACS Nano, 2019, 13, 1365-1384.

158. R. Kuai, X. Sun, W. Yuan, L. J. Ochyl, Y. Xu, A. Hassani Najafabadi, L. Scheetz, M.-Z. Yu, I. Balwani, A. Schwendeman and J. J. Moon, Journal of Controlled Release, 2018, 282, 131-139.

159. D. B. Horváthy, M. Simon, C. M. Schwarz, M. Masteling, G. Vácz, I. Hornyák and Z. Lacza, BioFactors, 2017, 43, 315-330.

160. K. Schandl, D. B. Horvathy, A. Doros, E. Majzik, C. M. Schwarz, L. Csonge, G. Abkarovits, L. Bucsi and Z. Lacza, International orthopaedics, 2016, 40, 2097-2104.

161. D. B. Horvathy, G. Vacz, A. Cselenyak, M. Weszl, L. Kiss and Z. Lacza, Surgical innovation, 2013, 20, 249-255.

162. I. M. Bjorge, S. Y. Kim, J. F. Mano, B. Kalionis and W. Chrzanowski, Biomaterials science, 2017, 6, 60-78.

163. G. H. Cui, J. Wu, F. F. Mou, W. H. Xie, F. B. Wang, Q. L. Wang, J. Fang, Y. W. Xu, Y. R. Dong, J. R. Liu and H. D. Guo, FASEB journal : official publication of the Federation of American Societies for Experimental Biology, 2018, 32, 654-668.

164. Y. Ma, L. Dong, D. Zhou, L. Li, W. Zhang, Y. Zhen, T. Wang, J. Su, D. Chen, C. Mao and X. Wang, Journal of cellular and molecular medicine, 2019, 23, 2822-2835.

165. Y. Wang, L. Zhang, Y. Li, L. Chen, X. Wang, W. Guo, X. Zhang, G. Qin, S. H. He, A. Zimmerman, Y. Liu, I. M. Kim, N. L. Weintraub and Y. Tang, International journal of cardiology, 2015, 192, 61-69.

166. J. A. Dougherty, N. Kumar, M. Noor, M. G. Angelos, M. Khan, C. A. Chen and M. Khan, Frontiers in physiology, 2018, 9, 1794.

167. A. Radeghieri, G. Savio, A. Zendrini, G. Di Noto, A. Salvi, P. Bergese and G. Piovani, Biochem Biophys Res Commun, 2017, 483, 706-711.

168. Y. Wang, D. Yu, Z. Liu, F. Zhou, J. Dai, B. Wu, J. Zhou, B. C. Heng, X. H. Zou, H. Ouyang and H. Liu, Stem cell research \& therapy, 2017, 8, 189.

169. S. S. Gu, N. Shi and M. P. Wu, Life sciences, 2007, 81, 702-709.

170. B. S. Ding, C. H. Liu, Y. Sun, Y. Chen, S. L. Swendeman, B. Jung, D. Chavez, Z. Cao, C. Christoffersen, L. B. Nielsen, S. R. Schwab, S. Rafii and T. Hla, JCI insight, 2016, 1, e87058. 
171. S. Van Linthout, M. Frias, N. Singh and B. De Geest, Handbook of experimental pharmacology, 2015, 224, 527-565.

172. X. Wang, J. Zhou and W. Wang, Current pharmaceutical design, 2015, 21, 1529-1544.

173. F. Spillmann, C. Trimpert, J. Peng, L. G. Eckerle, A. Staudt, K. Warstat, S. B. Felix, B. Pieske, C. Tschöpe and S. Van Linthout, Biochemical and Biophysical Research Communications, 2015, 466, 272-277.

174. C. M. Gibson, M. Kerneis, M. K. Yee, Y. Daaboul, S. Korjian, A. P. Mehr, P. Tricoci, J. H. Alexander, J. J. P. Kastelein, R. Mehran, C. Bode, B. S. Lewis, R. Mehta, D. Duffy, J. Feaster, M. Halabi, D. J. Angiolillo, D. Duerschmied, T. O. Ophuis and B. Merkely, American heart journal, 2019, 208, 81-90.

175. C. Gebhard, E. Rheaume, C. Berry, G. Brand, A. E. Kernaleguen, G. Theberge-Julien, M. A. Alam, C. Y. Lee, L. Boileau, M. Chabot-Blanchet, M. C. Guertin, M. A. Lavoie, J. Gregoire, R. Ibrahim, P. L'Allier and J. C. Tardif, PLoS One, 2017, 12, e0168448.

176. M. Mishra, I. Muthuramu, J. P. Aboumsallem, H. Kempen and B. De Geest, Int J Mol Sci, 2018, 19.

177. T. Tsatralis, A. Ridiandries, S. Robertson, L. Z. Vanags, Y. T. Lam, J. T. M. Tan, M. K. C. $\mathrm{Ng}$ and C. A. Bursill, Lipids in health and disease, 2016, 15, 150-150.

178. R. Gao, M. Watson, K. E. Callon, D. Tuari, M. Dray, D. Naot, S. Amirapu, J. T. Munro, J. Cornish and D. S. Musson, Journal of tissue engineering and regenerative medicine, 2018, 12, e620-e626.

179. T. Fuji, Y. Umeda, A. Nyuya, F. Taniguchi, T. Kawai, K. Yasui, T. Toshima, K. Yoshida, T. Fujiwara, A. Goel and T. Nagasaka, International journal of cancer, 2019, 144, 2169-2180.

180. E. Vila-Navarro, S. Duran-Sanchon, M. Vila-Casadesus, L. Moreira, A. Gines, M. Cuatrecasas, J. J. Lozano, L. Bujanda, A. Castells and M. Gironella, Clinical and translational gastroenterology, 2019, 10, e00029.

181. N. Asano, J. Matsuzaki, M. Ichikawa, J. Kawauchi, S. Takizawa, Y. Aoki, H. Sakamoto, A. Yoshida, E. Kobayashi, Y. Tanzawa, R. Nakayama, H. Morioka, M. Matsumoto, M. Nakamura, T. Kondo, K. Kato, N. Tsuchiya, A. Kawai and T. Ochiya, Nature Communications, 2019, 10, 1299.

182. Q. Jiang, X. Lu, P. Huang, C. Gao, X. Zhao, T. Xing, G. Li, S. Bao and H. Zheng, BioMed Research International, 2018, 2018, 10.

183. H. Honghai, Y. Haihui and X. Yong, Current Pharmaceutical Biotechnology, 2018, 19, 79-86.

184. H. Nakashima, R. Yoshida, A. Hirosue, K. Kawahara, J. Sakata, H. Arita, T. Yamamoto, R. Toya, R. Murakami, A. Hiraki, M. Shinohara, T. Ito, Y. Kuwahara and H. Nakayama, Tumor Biology, 2019, 41, 1010428319826853.

185. D. Turpin, M. E. Truchetet, B. Faustin, J. F. Augusto, C. Contin-Bordes, A. Brisson, P. Blanco and P. Duffau, Autoimmun Rev, 2016, 15, 174-183.

186. S. Wang, J. Gao and Z. Wang, Wiley Interdiscip Rev Nanomed Nanobiotechnol, 2019, 11, e1523.

187. L. A. Aqrawi, H. K. Galtung, B. Vestad, R. Ovstebo, B. Thiede, S. Rusthen, A. Young, E. M. Guerreiro, T. P. Utheim, X. Chen, O. A. Utheim, O. Palm and J. L. Jensen, Arthritis Res Ther, 2017, 19, 14.

188. W. Zhang, X. Zhou, H. Zhang, Q. Yao, Y. Liu and Z. Dong, Am J Physiol Renal Physiol, 2016, 311, F844-F851. 
189. G. Lou, Z. Chen, M. Zheng and Y. Liu, Exp Mol Med, 2017, 49, e346.

190. X. Jin, Y. Chen, H. Chen, S. Fei, D. Chen, X. Cai, L. Liu, B. Lin, H. Su, L. Zhao, M. Su, H. Pan, L. Shen, D. Xie and C. Xie, Clin Cancer Res, 2017, 23, 5311-5319.

191. J. Castillo, V. Bernard, F. A. San Lucas, K. Allenson, M. Capello, D. U. Kim, P.

Gascoyne, F. C. Mulu, B. M. Stephens, J. Huang, H. Wang, A. A. Momin, R. O. Jacamo, M. Katz, R. Wolff, M. Javle, G. Varadhachary, Wistuba, II, S. Hanash, A. Maitra and H. Alvarez, Ann Oncol, 2018, 29, 223-229.

192. J. Fredsoe, A. K. I. Rasmussen, P. Mouritzen, M. Borre, T. Orntoft and K. D. Sorensen, Int J Cancer, 2019, DOI: 10.1002/ijc.32296.

193. P. Li, X. Yu, W. Han, Y. Kong, W. Bao, J. Zhang, W. Zhang and Y. Gu, ACS Sens, 2019, 4, 1433-1441.

194. E. Reategui, K. E. van der Vos, C. P. Lai, M. Zeinali, N. A. Atai, B. Aldikacti, F. P. Floyd, Jr., H. K. A, V. Thapar, F. H. Hochberg, L. V. Sequist, B. V. Nahed, S. C. B, M. Toner, L. Balaj, T. T. D, X. O. Breakefield and S. L. Stott, Nat Commun, 2018, 9, 175.

195. H. Shao, J. Chung, K. Lee, L. Balaj, C. Min, B. S. Carter, F. H. Hochberg, X. O. Breakefield, H. Lee and R. Weissleder, Nat Commun, 2015, 6, 6999.

196. Y. Bei, P. Yu, D. Cretoiu, S. M. Cretoiu and J. Xiao, Adv Exp Med Biol, 2017, 998, 7188.

197. A. E. Berezin, A. A. Kremzer, Y. V. Martovitskaya, T. A. Samura and T. A. Berezina, BBA Clin, 2015, 3, 18-24.

198. S. Evans and D. L. Mann, Circ Res, 2013, 113, 242-244.

199. G. Chiva-Blanch, R. Suades, J. Crespo, G. Vilahur, G. Arderiu, T. Padro, D. Corella, J. Salas-Salvado, F. Aros, M. A. Martinez-Gonzalez, E. Ros, M. Fito, R. Estruch and L. Badimon, Int J Cardiol, 2016, 208, 147-149.

200. Q. Ji, Y. Ji, J. Peng, X. Zhou, X. Chen, H. Zhao, T. Xu, L. Chen and Y. Xu, PLoS One, 2016, 11, e0163645.

201. G. Di Noto, A. Bugatti, A. Zendrini, E. L. Mazzoldi, A. Montanelli, L. Caimi, M. Rusnati, D. Ricotta and P. Bergese, Biosensors and Bioelectronics, 2016, 77, 518-524.

202. L.-G. Liang, M.-Q. Kong, S. Zhou, Y.-F. Sheng, P. Wang, T. Yu, F. Inci, W. P. Kuo, L.J. Li, U. Demirci and S. Wang, Scientific Reports, 2017, 7, 46224.

203. K. Liang, F. Liu, J. Fan, D. Sun, C. Liu, C. J. Lyon, D. W. Bernard, Y. Li, K. Yokoi, M. H. Katz, E. J. Koay, Z. Zhao and Y. Hu, Nature Biomedical Engineering, 2017, 1, 0021.

204. C. Liu, X. Xu, B. Li, B. Situ, W. Pan, Y. Hu, T. An, S. Yao and L. Zheng, Nano Letters, 2018, 18, 4226-4232.

205. S. M. Santana, M. A. Antonyak, R. A. Cerione and B. J. Kirby, Physical Biology, 2014, 11, 065001.

206. J. S. Yang, J. C. Lee, S. K. Byeon, K. H. Rha and M. H. Moon, Analytical Chemistry, 2017, 89, 2488-2496.

207. M. Tong, Q. Chen, J. L. James, P. R. Stone and L. W. Chamley, Frontiers in Endocrinology, 2017, 8.

208. B. Whitehead, L. Wu, M. L. Hvam, H. Aslan, M. Dong, L. Dyrskjøt, M. S. Ostenfeld, S. M. Moghimi and K. A. Howard, Journal of Extracellular Vesicles, 2015, 4, 29685.

209. A. Rivas-Urbina, S. Benitez, A. Perez and J. L. Sanchez-Quesada, Frontiers in bioscience (Landmark edition), 2018, 23, 1220-1240. 
210. A. Trpkovic, I. Resanovic, J. Stanimirovic, D. Radak, S. A. Mousa, D. Cenic-Milosevic, D. Jevremovic and E. R. Isenovic, Critical Reviews in Clinical Laboratory Sciences, 2015, 52, 70-85.

211. M. P. Hermans and P. Valensi, Current opinion in endocrinology, diabetes, and obesity, 2018, 25, 118-129.

212. N. Clouet-Foraison, F. Gaie-Levrel, P. Gillery and V. Delatour, Journal, 2017, 55, 1453.

213. I. Rosado-Sánchez, E. Rodríguez-Gallego, J. Peraire, C. Viladés, P. Herrero, F. Fanjul, F. Gutiérrez, E. Bernal, R. Pelazas, M. Leal, S. Veloso, M. López-Dupla, J. Blanco, F. Vidal, Yolanda M. Pacheco and A. Rull, Clinical Science, 2019, 133, 997.

214. S. De Bruyne, T. Monteyne, M. Speeckaert Marijn and R. Delanghe Joris, Journal, 2017, $\mathbf{5 5}, 876$.

215. J. Wagner, M. Riwanto, C. Besler, A. Knau, S. Fichtlscherer, T. Röxe, M. Zeiher Andreas, U. Landmesser and S. Dimmeler, Arteriosclerosis, Thrombosis, and Vascular Biology, 2013, 33, 1392-1400.

216. L. S. Niculescu, N. Simionescu, G. M. Sanda, M. G. Carnuta, C. S. Stancu, A. C. Popescu, M. R. Popescu, A. Vlad, D. R. Dimulescu, M. Simionescu and A. V. Sima, PLOS ONE, 2015, 10, e0140958.

217. K. C. Vickers, B. T. Palmisano, B. M. Shoucri, R. D. Shamburek and A. T. Remaley, Nature Cell Biology, 2011, 13, 423.

218. D. Liu, M. Zhang, W. Xie, G. Lan, H.-P. Cheng, D. Gong, C. Huang, Y.-C. Lv, F. Yao, Y.-L. Tan, L. Li, X.-L. Zheng and C.-K. Tang, Biochemical and Biophysical Research Communications, 2016, 472, 418-424.

219. K. C. Vickers, S. R. Landstreet, M. G. Levin, B. M. Shoucri, C. L. Toth, R. C. Taylor, B. T. Palmisano, F. Tabet, H. L. Cui, K.-A. Rye, P. Sethupathy and A. T. Remaley, Proceedings of the National Academy of Sciences, 2014, 111, 14518.

220. C. Paganini, U. C. Palmiero, G. Pocsfalvi, N. Touzet, A. Bongiovanni and P. Arosio, Biotechnology journal, 2019, DOI: 10.1002/biot.201800528, e1800528.

221. A. Goes and G. Fuhrmann, ACS infectious diseases, 2018, 4, 881-892.

222. M. Faria, M. Bjornmalm, K. J. Thurecht, S. J. Kent, R. G. Parton, M. Kavallaris, A. P. R. Johnston, J. J. Gooding, S. R. Corrie, B. J. Boyd, P. Thordarson, A. K. Whittaker, M. M. Stevens, C. A. Prestidge, C. J. H. Porter, W. J. Parak, T. P. Davis, E. J. Crampin and F. Caruso, Nature nanotechnology, 2018, 13, 777-785.

223. X. Li, M. Soler, C. Szydzik, K. Khoshmanesh, J. Schmidt, G. Coukos, A. Mitchell and H. Altug, Small (Weinheim an der Bergstrasse, Germany), 2018, 14, e1800698.

224. K. Powell, Nature, 2018, 563, 172-175.

225. R. Desplantes, C. Leveque, B. Muller, M. Lotierzo, G. Ferracci, M. Popoff, M. Seagar, R. Mamoun and O. El Far, Sci Rep, 2017, 7, 1032.

226. C. Montis, S. Busatto, F. Valle, A. Zendrini, A. Salvatore, Y. Gerelli, D. Berti and P. Bergese, Advanced Biosystems, 2018, 2, 1700200.

227. J. Tang, D. Shen, T. G. Caranasos, Z. Wang, A. C. Vandergriff, T. A. Allen, M. T. Hensley, P. U. Dinh, J. Cores, T. S. Li, J. Zhang, Q. Kan and K. Cheng, Nat Commun, $2017, \mathbf{8}, 13724$.

228. A. K. Silva, R. Di Corato, T. Pellegrino, S. Chat, G. Pugliese, N. Luciani, F. Gazeau and C. Wilhelm, Nanoscale, 2013, 5, 11374-11384. 
229. M. Weiss, J. P. Frohnmayer, L. T. Benk, B. Haller, J. W. Janiesch, T. Heitkamp, M. Borsch, R. B. Lira, R. Dimova, R. Lipowsky, E. Bodenschatz, J. C. Baret, T. VidakovicKoch, K. Sundmacher, I. Platzman and J. P. Spatz, Nat Mater, 2018, 17, 89-96. 


\section{Table of Content}

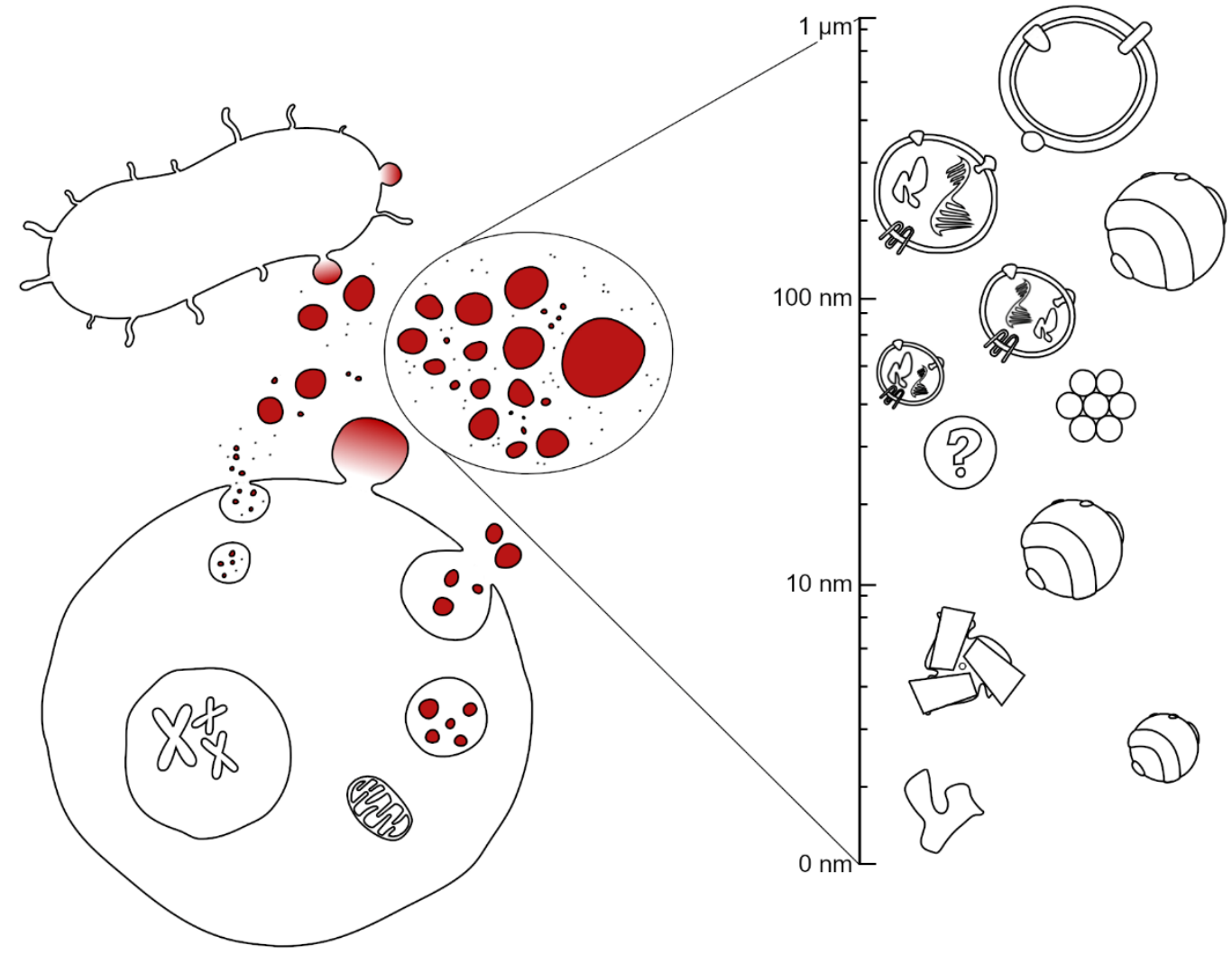

